(C) The Authors 2016. This is an Open Access article, distributed under the terms of the Creative

Commons Attribution licence (http://creativecommons.org/licenses/by/4.0/), which permits unrestricted

re-use, distribution, and reproduction in any medium, provided the original work is properly cited.

\title{
Could gestational diabetes mellitus be managed through dietary bioactive compounds? Current knowledge and future perspectives
}

\author{
Carmela Santangelo ${ }^{1 *}$, Alessandra Zicari ${ }^{2}$, Elisabetta Mandosi ${ }^{3}$, Beatrice Scazzocchio ${ }^{1}$, Emanuela Mari $^{2}$, \\ Susanna Morano ${ }^{3}$ and Roberta Masella ${ }^{1}$ \\ ${ }^{1}$ Department of Veterinary Public Health and Food Safety, Unit of Nutrition, Italian National Institute of Health, Viale Regina \\ Elena 299, 00161 Rome, Italy \\ ${ }^{2}$ Department of Experimental Medicine, 2nd Section of Cell Pathology, Sapienza University of Rome, Viale Regina Elena 324 , \\ 00161 Rome, Italy \\ ${ }^{3}$ Department of Experimental Medicine, Section of Medical Pathophysiology, Food Science and Endocrinology, Sapienza \\ University of Rome, Viale Regina Elena 324, 00161 Rome, Italy
}

(Submitted 26 March 2015 - Final revision received 11 November 2015 - Accepted 23 December 2015 - First published online 16 February 2016)

\section{Abstract}

Gestational diabetes mellitus (GDM) is a serious problem growing worldwide that needs to be addressed with urgency in consideration of the resulting severe complications for both mother and fetus. Growing evidence indicates that a healthy diet rich in fruit, vegetables, nuts, extra-virgin olive oil and fish has beneficial effects in both the prevention and management of several human diseases and metabolic disorders. In this review, we discuss the latest data concerning the effects of dietary bioactive compounds such as polyphenols and PUFA on the molecular mechanisms regulating glucose homoeostasis. Several studies, mostly based on in vitro and animal models, indicate that dietary polyphenols, mainly flavonoids, positively modulate the insulin signalling pathway by attenuating hyperglycaemia and insulin resistance, reducing inflammatory adipokines, and modifying microRNA (miRNA) profiles. Very few data about the influence of dietary exposure on GDM outcomes are available, although this approach deserves careful consideration. Further investigation, which includes exploring the 'omics' world, is needed to better understand the complex interaction between dietary compounds and GDM.

Key words: Gestational diabetes mellitus: Mediterranean diet: Dietary polyphenols: Adipokines: Molecular mechanisms: PUFA: MicroRNA

Gestational diabetes mellitus (GDM) is the most common metabolic disorder during pregnancy ${ }^{(1)}$, and its prevalence is increasing worldwide ${ }^{(2)}$. Women with GDM are at a high risk of developing type 2 diabetes (T2D) later in life ${ }^{(1)}$; in addition, the higher baseline BMI and weight gain often found after GDM occurrence increase the risk of progression from GDM to T2 $\mathrm{D}^{(3)}$. Moreover, uncontrolled GDM is associated with a detrimental intra-uterine environment, which leads to fetal complications and an increased risk for the child of developing obesity and metabolic disorders ${ }^{(4,5)}$.

In response to the marked rise in GDM, it is of paramount importance to identify appropriate treatments to prevent maternal and fetal complications associated with this disease.

At present, the management of GDM is a big challenge because of its heterogeneity (i.e. ethnic as well as intra-, and inter-country differences $)^{(2,6,7)}$, and the incomplete knowledge of its pathophysiology ${ }^{(8)}$. As a result, standardised guidelines for GDM are difficult to arrive at worldwide, as are the intervention strategies aimed at preventing or/and reducing the burden of this disorder. In addition, obesity and maternal overweight have been considered as the main risk factors for $\mathrm{GDM}^{(1)}$; the reduction of these risk factors is essential for the well-being of mother and offspring ${ }^{(5)}$.

Pre-pregnancy and early pregnancy are the best periods for a dietary intervention to control weight in order to prevent the long-lasting effects of maternal diabetes or obesity ${ }^{(9)}$.

There is increasing evidence that the dietary patterns having beneficial effects both in prevention and management of diabetes are characterised by high consumption of plant foods (e.g. whole grains, fruit, vegetables and extra-virgin olive oil, nuts)

Abbreviations: Akt, protein kinase B; ALA, $\alpha$-linolenic acid; AMPK, AMP-activated protein kinase; AT, adipose tissue; C3G, cyanidin-3-glucoside; EGCG, epigallocatechin gallate; FA, fatty acids; FABP, FA-binding protein; GDM, gestational diabetes mellitus; IR, insulin resistance; IRS-1, insulin receptor substrate 1; LA, linoleic acid; LC-PUFA, long-chain PUFA; MedDiet, Mediterranean-style diet; miRNA, microRNA; RSV, resveratrol; T2D, type 2 diabetes. 
and fish, and low consumption of animal-based, high-fat, processed foods, that is, the Mediterranean-style diet (MedDiet) ${ }^{(10)}$. The MedDiet is a primarily plant-based dietary pattern that has been strongly associated with lower incidence of CVD, and neoplastic diseases, and an overall reduced mortality ${ }^{(11,12)}$. Adherence to the MedDiet correlates with better glycaemic control, a reduced risk of both total and cardiovascular mortality in diabetic subjects in Mediterranean populations ${ }^{(13-15)}$ and a lower risk of metabolic syndrome and CVD in nonMediterranean populations ${ }^{(16-19)}$. These findings indicate that the adoption of the MedDiet model by populations having different dietary habits is effective in reducing the risk of noncommunicable disorders.

The short-term - 4 weeks - consumption of a DASH diet (Dietary Approaches to Stop Hypertension), rich in fruits, vegetables, whole grains and lower amounts of SFA, improved pregnancy outcomes among GDM women ${ }^{(20)}$. Pre-pregnancy adherence to healthy dietary patterns ${ }^{(21)}$ and the MedDiet is associated with lower incidence of GDM and a better degree of glucose tolerance in no-GDM pregnant women ${ }^{(22)}$.

In any case, the mechanisms underlying the protective effects of the MedDiet are not clear as yet. The high MUFA:SFA ratio, the increased level of PUFA, the low content of trans-fatty acids (FA) and the high content of fibres, vitamins, mineral salts and phytochemicals compounds may contribute to the beneficial effects of MedDiet ${ }^{(23-25)}$. Over the past years, researchers have focused their attention on the role of plantderived, functional foods and their bioactive compounds in the control of various aspects of diabetes mellitus ${ }^{(26,27)}$. Among the known natural bioactive components, polyphenols have been shown to have anti-hyperglycaemic effects, antioxidant and anti-inflammatory activities and no side effects ${ }^{(27-29)}$. In addition, the increasing demand of non-fish source of $n-3$ PUFA is worth considering, in view of the beneficial effects of these FA in GDM women ${ }^{(24)}$, and during pregnancy in general, not to mention the worldwide increase in the number of vegetarians and vegans ${ }^{(30)}$.

The knowledge of how (i.e. molecular mechanisms) and where (i.e. targets) a given biocompound acts is of crucial importance to better understand the mechanisms governing the dietary impact on the metabolic system in GDM.

We found a good number of articles in English published up to August 2015 by searching in PubMed, using the key words 'gestational diabetes mellitus', 'diabetes', 'insulin resistance', 'hyperglycaemia', 'adipokines', 'inflammation', 'microRNAs', 'PUFAs', molecular mechanisms'; these key words were searched in combination with the key words 'Mediterranean diet', vegetables food', 'polyphenols', 'phytochemicals', 'bioactive compounds'. Data regarding the association between plantderived compounds and GDM are scarce. This review discusses the current knowledge and issue about the impact of dietary polyphenols on the mechanisms and/or factors regulating glucose homoeostasis, inflammation and adipose tissue (AT) function in metabolic alterations associated with GDM. The role of $n-3$ FA in pregnancy is also addressed. From all these data, MedDiet bioactive compounds appear to be more and more useful players to be included in future research approaches designed to prevent and treat GDM.

\section{Dietary polyphenols}

The MedDiet is characterised by a high intake of vegetable food $^{(31)}$, and polyphenols are the biggest class of plant-derived bioactive compounds ${ }^{(32-34)}$. These phytochemicals are found in quite variable quantities in fruit, vegetables, cereals, nuts, tea, wine, chocolate, olives, extra-virgin olive oil and plant-derived foodstuffs, as well as spices and algae ${ }^{(34-36)}$. Even more data link polyphenol intake with both health promotion and the prevention of non-communicable diseases such as CVD, stroke, T2D and some cancers ${ }^{(27-29,37)}$. Polyphenols are a complex class of compounds having a phenolic ring in their structure; they can be classified on the basis of the numbers of phenol rings they contain and the structural elements that bind these rings ${ }^{(32,35)}$. The majority of polyphenols exist as glycosides, esters, polymers and in hydroxylated form ${ }^{(35,37)}$. They are extensively modified throughout stomach, small intestine, colon and liver ${ }^{(38)}$; thus, a single polyphenol can generate several active metabolites ${ }^{(39)}$. Because of their chemical structures, dietary polyphenols exert multiple activities by interacting with several molecular pathways and cellular components including microRNA (miRNA) ${ }^{(28,37,40,41)}$. The main classes of polyphenols are flavonoids, phenolic acids, stilbenes and lignans ${ }^{(32,35)}$. Flavonoids are the most abundant class of polyphenols in our diet and include different subclasses, that is, flavonols, flavones, flavanols, flavanones, anthocyanidins and isoflavones ${ }^{(42,43)}$ (Fig. 1). The evaluation of the actual contribution of dietary polyphenols to human health is challenging, as several factors come into play: food-related factors (i.e. amount consumed, food content and bioavailability) and host-related factors (i.e. genetics, obesity, pregnancy and gut microbiota) ${ }^{(44)}$. Moreover, chemical structure, synergistic effects among different polyphenols and interaction with cellular components (e.g. membrane, proteins, enzymes, receptors and transcription factors) render the evaluation quite hard ${ }^{(44,45)}$. An accurate measurement of the exposure to specific compounds will make it possible to associate these factors with health status and disease outcomes. To this end, efforts have been made to assess the following: (i) the level of adherence to the MedDiet, by the Mediterranean Dietary Serving Score, which accounts for the consumption of foods and food groups per meal, day or week ${ }^{(46)}$; (ii) the content of polyphenols in food and their metabolism $^{(34)}$, as well as the human intake of total and specific polyphenols, by the creation of online database (e.g. PhenolExplorer and United States Department of Agriculture database) $)^{(34,42,43,47-49)}$; and (iii) novel biomarkers for polyphenol ingestion in biological fluids, by measuring food metabolome ${ }^{(50-52)}$.

\section{Glucose homoeostasis regulation}

GDM is defined as carbohydrate intolerance during pregnancy ${ }^{(1)}$. Pregnancy is characterised by a complex process of endocrine-metabolic changes, including physiological insulin resistance (IR), necessary to ensure the supply of nutrients to the fetus and to adequately prepare the maternal organism for childbirth and lactation ${ }^{(53)}$. GDM develops when the pregnant woman is not able to produce an adequate insulin response to compensate for physiological $\mathrm{IR}^{(54)}$. IR during pregnancy is uniquely associated with a decrease in insulin receptor substrate 1 (IRS-1) tyrosine phosphorylation, primarily because of a 


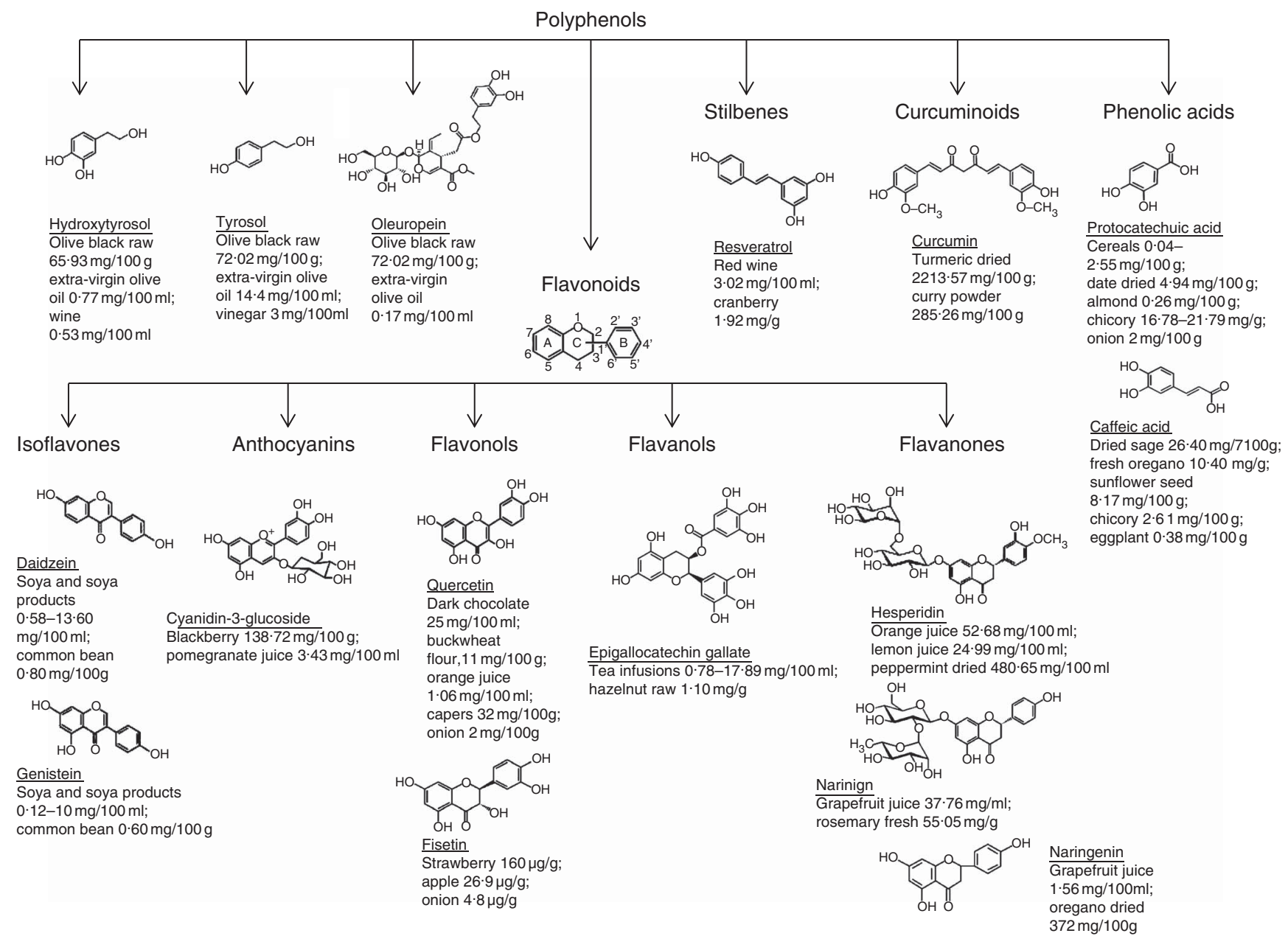

Fig. 1. Chemical structure and main dietary source of polyphenols discussed in this review regarding their capability to modulate glucose metabolism signalling.

decreased expression of IRS-1 protein $^{(55)}$. Nevertheless, in GDM subjects, there is an additional decrease in tyrosine phosphorylation of the insulin receptor $\beta$ subunit, associated with further decreases in glucose transport activity ${ }^{(55,56)}$. Lower levels of tyrosine kinase receptor activity (30-40\%), IRS-1 expression and activation, and GLUT4, in fact, have been detected in pregnancy with respect to pre-pregnancy status ${ }^{(55,56)}$. Specifically, IRS-1 tyrosine phosphorylation has been found to be significantly reduced in muscle from pregnant control and obese GDM subjects, as reflected by a 23 and $44 \%$ reduction, respectively, compared with non-pregnant women ${ }^{(57)}$. AT, through a large arrays of secreted factors, participates in the induction and regulation of IR both in non-pregnant and pregnant subjects ${ }^{(58)}$. Maternal pre-pregnancy obesity decreases insulin sensitivity and positively associates with the risk of $\mathrm{GDM}^{(59)}$. A recent study has shown that AT inflammasome (caspase-1 and IL-1 $\beta$ ) is involved in the development of IR in GDM-complicated pregnancies ${ }^{(60)}$. Increased IL- $1 \beta$ expression has been observed in AT from GDM women; incubation of AT with IL- $1 \beta$ results in a significant attenuation of phosphorylated IRS-1 protein expression, GLUT4 mRNA and protein expression and glucose uptake, indicating the importance of inflammasome in the pathophysiology of $\mathrm{GDM}^{(60)}$.
Over the past years, the role of miRNA in gene regulation has been gaining attention; miRNA are implicated in regulating cholesterol biosynthesis, carbohydrate and lipid metabolism ${ }^{(61)}$, as well as in insulin production, secretion and action ${ }^{(62)}$ (i.e. in glucose homoeostasis) ${ }^{(62-65)}$, by interacting with specific mRNA targets $^{(66)}$. Accordingly, miRNA have been explored in GDM with the aim of using them as early biomarkers of disease ${ }^{(67-70)}$, as they are present in the blood or other biological fluids ${ }^{(67,71)}$. To date, few investigations have been performed; two studies conducted in China have found decreased levels of miR-29a, -132 -and -222(69) , and increased levels of miR-16-5p, miR-17-5p, miR-19a-3p, miR-19b-3p and miR-20a-5p, in gestational weeks $16-19$ in the serum of pregnant women who later developed GDM in gestational weeks 25-28, with respect to women who did not develop $\mathrm{GDM}^{(70)}$. However, hyperglycemic non-pregnant rodents have shown opposite expression of mir-29 and mir-132 families. MiR-29 family is involved in the insulin-signalling pathway; muscle, fat and liver from hyperglycaemic Goto-Kakizaki rats exhibit up-regulation of miR-29a and miR-29b ${ }^{(72)}$. High glucose induces the up-regulation of miR29a associated ${ }^{(72)}$ with the decrease in IRS-1, downstream kinase Akt and glycogen synthase kinase 3 $\beta$, (GSK3 $\beta$ ) proteins, in both rat myocytes ${ }^{(73)}$ and human pancreatic $\beta$-cells ${ }^{(74)}$. 
MiR-132 expression is up-regulated in pancreatic islets of pre-diabetic (6 weeks old) and diabetic $\mathrm{db} / \mathrm{db}$ mice (14-20 weeks) ${ }^{(75)}$; this increase improved glucose-stimulated insulin release and increased cell proliferation, which suggests that the modification of miR-132 levels might contribute to compensatory $\beta$-cell mass expansion elicited in response to $\mathrm{IR}^{(75)}$. In GDM women, the up-regulation of miR-222 has been found to be associated with reduced protein levels of both oestrogen receptor (ER)- $\alpha$ and GLUT4 in omental AT, obtained at the time of caesarean delivery, and with increased serum estradiol levels ${ }^{(76)}$. In consideration of these findings, we may assume that miRNA are expressed in a species-, tissue-specific and time-dependent manner.

Furthermore, miRNA profiles of peripheral blood mononuclear cells isolated from Brazilian GDM women, obtained by using microarray platforms, have identified ten miRNA that seemed to be specific for GDM, namely, miR-101, miR-1180, miR-1268, miR-181a, miR-181d, miR-26a, miR-29a, miR-29c, miR-30b and miR- $595^{(67)}$.The target genes of most of these miRNA are involved in insulin signalling, angiogenesis, IR and AT dysfunction ${ }^{(66)}$. It is noteworthy that miR-181a is increased in the serum of diabetic patients, as well as in IR cultured hepatocytes and liver ${ }^{(77)}$. Inhibition of miR-181a by antisense oligonucleotides restores insulin sensitivity in hepatocytes, thus providing evidence of a potential therapeutic strategy for treating IR and $\mathrm{T} 2 \mathrm{D}^{(77)}$. On the other hand, miR-30 belonging to the miR-30 family that has a key role in angiogenesis ${ }^{(78)}$ might be involved in the hyper capillarisation of the placenta in women with mild hyperglycaemia ${ }^{(79,80)}$. Furthermore, miR-30 family members increase in abundance during the differentiation of pancreatic islet-derived mesenchymal cells into hormoneproducing islet-like cell aggregates, thus indicating their participation in the regulatory signalling of the embryonic development of human pancreatic islets ${ }^{(81)}$. However, the miRNA modifications so far observed in GDM women result from a limited number of screened subjects (from six to twenty). In addition, people from different countries appear to have different miRNA profiles, except for miR-29, in the same metabolic condition. In conclusion, although the above data provide evidence that miRNA are promising, non-invasive biomarkers of GDM, further research with larger cohorts is warranted.

\section{Polyphenols effects}

The maintenance of glucose homoeostasis is extremely important for human physiology ${ }^{(82)}$. Growing evidence indicates that polyphenols, contained in fruits and vegetables, might influence glucose homoeostasis by several mechanisms such as by (i) inhibiting carbohydrate digestion and glucose absorption in the intestine, (ii) stimulating insulin secretion from pancreatic $\beta$-cells, (iii) modulating glucose release from liver and (iv) activating insulin receptors and glucose uptake in insulin-sensitive tissues ${ }^{(83)}$. The bioactive food components can modify gene expression and regulate different signalling pathways, thus affecting muscle, liver, pancreatic $\beta$-cells, hypothalamus and AT functions, thereby regulating glucose homoeostasis ${ }^{(84,85)}$. This regulatory activity occurs also by modulating miRNA gene expression $^{(40,86-89)}$ (Fig. 2). Isoflavones, anthocyanins, flavanols

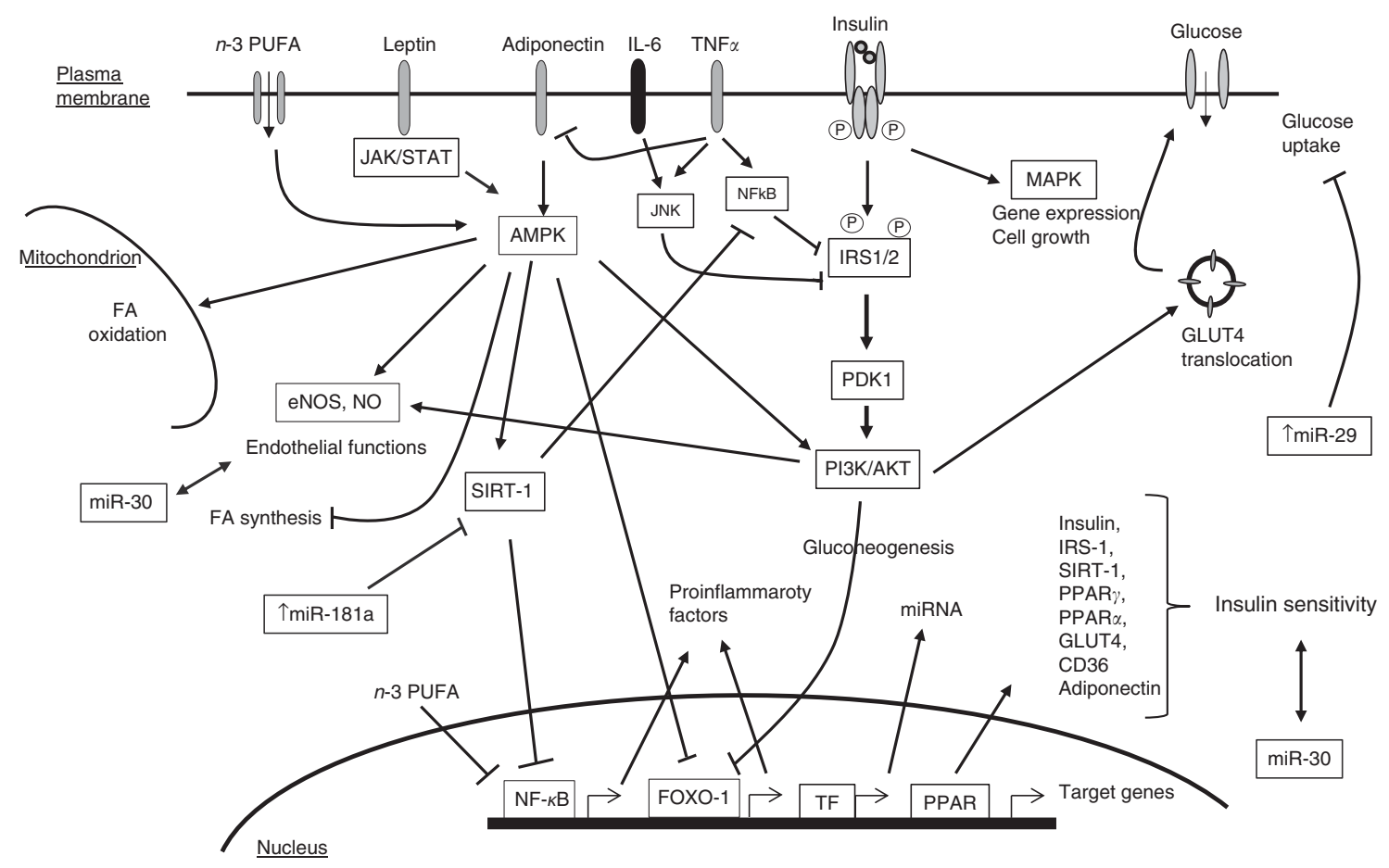

Fig. 2. Crosstalk among signalling pathways in regulating glucose metabolism. All of the factors that appear in this scheme are potential points of action of polyphenols. $\longrightarrow$, Activation; $\longrightarrow$, inhibition; $\longleftrightarrow$, modulation; JAK/STAT, Janus kinase/signal transducer and activator of transcription; AMPK, AMP-activated protein kinase; JNK, c-Jun N-terminal kinase; IRS1/2, insulin receptor substrate 1/2; MAPK, mitogen-activated protein kinases; PDK1, 3-phosphoinositide-dependent protein kinase-1; PI3K, phosphatidylinositol-3-kinase; Akt, protein kinase B; SIRT-1, sirtuin 1; NO, nitric oxide; eNOS, endothelial NO synthase; FOXO1, forkhead box protein $\mathrm{O} 1$; TF, transcription factors; miRNA, microRNA; FA, fatty acids. 
and catechins appear to enhance $\beta$-cell function and glucose tolerance in animal models and humans and to protect against diabetes $^{(29)}$. Genistein and daidzein are the major dietary isoflavones present primarily in soya foods ${ }^{(90)}$. Long-term genistein exposure (1-10 $\mu \mathrm{m}$ for $48 \mathrm{~h})$ improved glucose-stimulated insulin secretion (GSIS) in mouse and human pancreatic islets ${ }^{(91)}$; this effect appears to be mediated by cyclic AMP/protein kinase A signalling activation and increased intracellular $\mathrm{Ca}^{2+}$ levels ${ }^{(91)}$ (Table 1).

The flavanol epigallocatechin gallate (EGCG), a main component of green tea extract, preserves the insulin secretory machinery; EGCG $(10 \mu \mathrm{m}$ for $48 \mathrm{~h})$ stimulates the activation of the IRS-2 signalling in rat insulinoma pancreatic $\beta$-cells (RIN-m5F), also under chronic hyperglycaemia ${ }^{(92)}$. EGCG increases the activity of AMP-activated protein kinase (AMPK) through $\mathrm{Thr}^{172}$ phosphorylation, further strengthening the hypothesis that AMPK is involved in counteracting the glucolipotoxicity induced by high-glucose condition ${ }^{(92)}$. AMPK is an energy-sensing enzyme recognised as a master regulator of whole-body energy homoeostasis; its activation increases GLUT4 expression and membrane translocation in skeletal muscle, thereby improving glucose uptake ${ }^{(93)}$. In this regard, AMPK has been considered as one of the targets of the insulinsensitising drugs metformin and thiazolidinediones ${ }^{(93)}$.

EGCG $(20,40 \mu \mathrm{m}$ for $24 \mathrm{~h})$ improved the insulin-stimulated glucose uptake also in dexamethasone-treated skeletal muscle cells L6, associated with an increased AMPK phosphorylation and GLUT4 membrane translocation ${ }^{(94)}$. Furthermore, the dexamethasone-stimulated inactivation of IRS-1 because of increased Ser ${ }^{307}$ phosphorylation has been significantly reversed by EGCG treatment ${ }^{(94)}$. Results from the miRNA profiling suggest that EGCG may exert its biological functions through up- or down-regulating multiple miRNA as well ${ }^{(95)}$. In particular, EGCG $(50 \mathrm{mg} / \mathrm{l}$ for $5 \mathrm{~h})$, grape seed $(100 \mathrm{mg} / \mathrm{l}$ for $5 \mathrm{~h})$ and cocoa proanthocyanidin extracts $(100 \mathrm{mg} / \mathrm{l}$ for $5 \mathrm{~h}$ ) down-regulated miR-30b expression in human hepatocellular carcinoma HepG2 cells ${ }^{(78)}$. A longer EGCG $(100 \mu \mathrm{m}$ for $24 \mathrm{~h})$ treatment reduced miR-181d and miR-222 expression as well, in HepG2 cells ${ }^{(95)}$.

Anthocyanins are widely distributed in the human diet through berries, fruits, vegetables and red wine ${ }^{(96)}$. Pretreatment with bayberry fruit extracts $(0.5 \mu \mathrm{mol} / 1$ cyanidin-3glucoside $(\mathrm{C} 3 \mathrm{G})$ for $12 \mathrm{~h}$ ) up-regulated pancreatic duodenal homeobox-1 gene expression, which is associated with increased levels of insulin-like growth factor-II gene transcript and insulin, in rat insulinoma cell line INS-1 $\beta$-cells ${ }^{(97)}$.

We have shown that C3G (10.50 $\mu$ for $18 \mathrm{~h})$ and its metabolite protocatechuic acid (PCA; $100 \mu \mathrm{m}$ for 18h) increased glucose uptake and GLUT4 membrane translocation in murine adipocytes and visceral human adipocytes ${ }^{(98-100)}$. Specifically, PCA appeared to exert insulin-like effects by stimulating IRS-1 tyrosine phosphorylation and Akt activation ${ }^{(98-100)}$.

Caffeic acid, naringenin and quercetin $\left(10^{-6} \mu \mathrm{M}\right.$ for $72 \mathrm{~h}$ each), present in many plants, enhance GSIS and glucose sensitivity in rat pancreatic INS-1E cells ${ }^{(101)}$. These compounds differently modulate gene expression profiles to improve $\beta$-cell survival and function during glucotoxicity (e.g. naringenin and quercetin up-regulated GLUT2, glucokinase, AKT1, whereas caffeic acid increased AKT2 and all the three compounds increased INS-1, mRNA expression) ${ }^{(101)}$. Similarly, curcumin (5-15 $\mu \mathrm{m}$ for $24 \mathrm{~h})$, a yellow pigment isolated from Curcuma Longa, increases insulin gene expression and GSIS in a dose-dependent manner in INS-1 cells ${ }^{(102)}$. In doing so, curcumin up-regulates the expression of GLUT2, the phosphorylation of IRS-1, phosphatidylinositol-3-kinase (PI3K) and Akt, suggesting that curcumin prevents the high-glucose-induced reduction of insulin expression and secretion by activating the PI3K/Akt/GLUT2 pathway in INS-1 cells ${ }^{(102)}$. Curcumin treatment modulates the expression profile of several miRNA, including up-regulation of miRNA-26a in A549 human lung adenocarcinoma cell line (curcumin: $15 \mu \mathrm{M}$ for $48 \mathrm{~h})^{(103)}$ and miR-181a in BxPC-3 human pancreatic carcinoma cell line (curcumin: $10 \mu \mathrm{m}$ for $72 \mathrm{~h})^{(104)}$.

Consistent with in vitro studies, animal intervention studies showed that supplementation with genistein $(0.2 \mathrm{~g} / \mathrm{kg}$ diet $)$ or daidzein $(0.2 \mathrm{~g} / \mathrm{kg}$ diet $)$ for 9 weeks preserved $\beta$-cells and reduced blood glucose levels by inducing insulin secretion, in non-obese diabetic mice ${ }^{(105)}$. Similarly, administration of $0 \cdot 1 \mathrm{ml}$ of bayberry fruit extracts (containing $150 \mu \mathrm{g}$ of $\mathrm{C} 3 \mathrm{G}$ ) $/ 10 \mathrm{~g}$ of body weight twice per day for $30 \mathrm{~d}$ significantly reduced blood glucose and improved glucose tolerance in streptozotocininduced diabetic mice ${ }^{(97)}$.

Changes in the expression of a large number of different miRNA have been observed after each polyphenol supplementation $^{(88)}$. MiRNA profile expression was evaluated in the livers of wild-type (C57B6/J) mice or apoE-/- mice fed diets supplemented with different polyphenols (including quercetin, hesperidin, naringenin, proanthocyanidin, caffeic acid, curcu$\min )^{(88,106)}$. MiR-29a and miR-30b expression were downregulated by almost all the tested polyphenols; miR-222 was down-regulated by caffeic acid $(300 \mathrm{mg} / \mathrm{d}$ for 2 weeks) and hesperidin (30 mg/d for 2 weeks); miR-181a was down-regulated by curcumin $(30 \mathrm{mg} / \mathrm{d}$ for 2 weeks) and hesperidin and up-regulated by naringin $(30 \mathrm{mg} / \mathrm{d}$ for 2 weeks), quercetin $(30 \mathrm{mg} / \mathrm{d}$ for 2 weeks) and proanthocyanidin $(300 \mathrm{mg} / \mathrm{d}$ for 2 weeks); miR-132 was up-regulated by naringin ${ }^{(88)}$. This study highlights the importance of miRNA as modulators of dietary polyphenols activities, in vivo(88).

Human intervention trials and cohort studies have reported that dietary supplementation with $22.5 \mathrm{~g}$ of whole blueberry twice daily (1462 mg of total phenolics, $668 \mathrm{mg}$ of anthocyanins) for 6 weeks resulted in blood glucose concentration reduction and in insulin sensitivity improvement in obese, non-diabetic, IR subjects ${ }^{(107)}$. Data from three prospective cohort studies involving 200000 US men and women showed that a higher consumption of anthocyanin-rich fruit is associated with a lower risk of $\mathrm{T}_{2} \mathrm{D}^{(108)}$. Collectively, anthocyanins and its glycosides, alone or in combination, improve glucose homoeostasis by influencing $\beta$-cell mass and function, insulin sensitivity, glucose uptake and insulin signalling ${ }^{(85)}$.

There is no doubt that dietary polyphenols have beneficial effects on $\beta$-cell function and glucose homoeostasis taking into account that most of them are capable of modulating almost all the players, including several miRNA, in the glucose uptake machinery. Although promising data have been obtained so far, no information on the effects of these bioactive compounds in GDM setting are available as yet. 


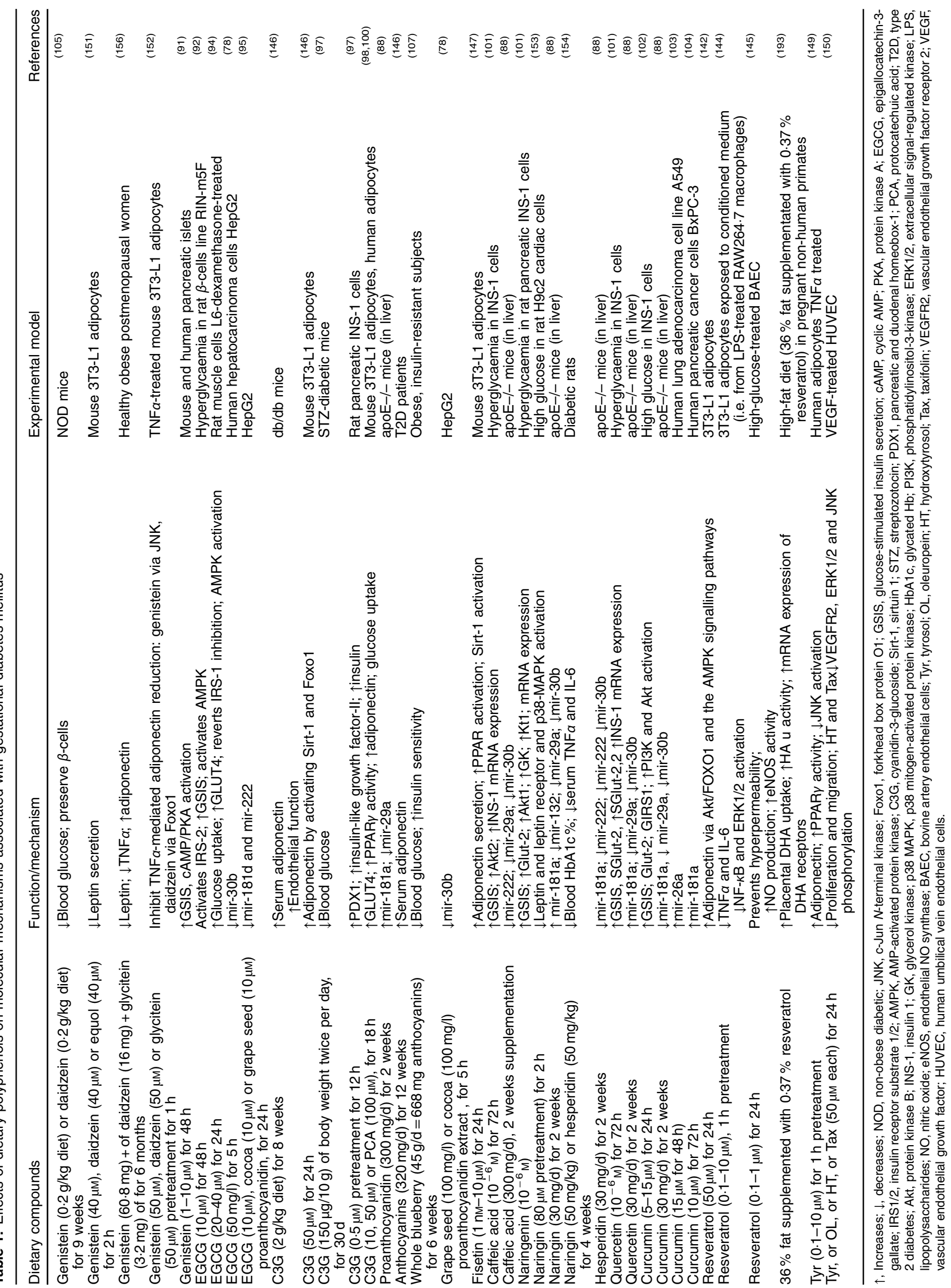




\section{Adipokines and gestational diabetes}

It is well known that adipocyte-derived cytokines (adipokines) are involved in the modulation of a wide range of physiological processes including lipid metabolism, atherosclerosis, angiogenesis and insulin sensitivity ${ }^{(109,110)}$. The human gestational tissues, as well as AT, produce and release a large array of pro-inflammatory cytokines; the activation of some inflammatory pathways is necessary to induce maternal IR, which is required for the progression of normal gestation $^{(9,111,112)}$. GDM associates with the amplification of the low-grade inflammation already existing in normal pregnancy ${ }^{(113,114)}$. Indeed, serum TNF $\alpha$, IL- $1 \beta$ and IL-6 levels are higher in GDM women as compared with control pregnant women $^{(115)}$. Notably, pre-pregnant obesity in GMD women worsens this inflammatory picture by up-regulating TNF $\alpha$, IL- $1 \beta$ and/or leptin, and by down-regulating genes involved in AT lipid metabolism such as PPAR $\alpha, P P A R \delta, P P A R \gamma$, retinoid $\mathrm{X}$ receptor- $\alpha(R X R \alpha)$ and sterol regulatory element-binding protein-1c (SREBP1c), in $\mathrm{AT}^{(109)}$

Over the past years, various adipokines such as adiponectin and leptin have been shown to play a role in normal pregnancy, as well as in complications of pregnancy including $\mathrm{GDM}^{(9,110,116,117)}$. Low adiponectin serum levels appear to be linked with T2D and $\mathrm{IR}^{(118)}$. A study conducted on 445 pregnant women demonstrated that lower levels of adiponectin during the first trimester of pregnancy are associated with increased risk of developing GDM during the second trimester, independently of other early pregnancy major risk factors ${ }^{(119)}$. Further, a nested case-control study showed that lower adiponectin levels measured 6 years before pregnancy were associated with a 5-fold increased risk of developing $\mathrm{GDM}^{(120)}$. Thus, an early low adiponectin expression, which most likely reflects pre-existing IR, could be considered a useful biomarker to identify women at high risk for GDM and allow for early therapeutic interventions ${ }^{(120)}$. Adiponectin acts as an insulin-sensitising agent, and its action is complex and incompletely defined, but the collected evidence suggests that, by binding with its receptors, adiponectin activates three key signalling pathways in muscle and liver: AMPK, p38 mitogen-activated protein kinase (p38 MAPK) and $\operatorname{PPAR}^{(121)}$. The activation of these pathways results in FA oxidation (FAO) and glucose uptake in skeletal muscle, and in the inhibition of gluconeogenesis in the liver ${ }^{(121)}$. Reduced adiponectin could be held accountable for the lower FAO observed in placentas of GDM women compared with the control group ${ }^{(122)}$. Adiponectin gene expression, processing and secretion is up-regulated by PPAR $\gamma$ agonist; PPAR $\gamma$ activation results in increased insulin sensitivity, in skeletal muscle and liver, by inducing the release of insulin-sensitising adipokines including adiponectin ${ }^{(123)}$. Administration of adiponectin to diabetic mice ${ }^{(124)}$ and obese pregnant mice enhances insulin activity $^{(125)}$, prevents fetal overgrowth ${ }^{(125)}$, normalises placental insulin/mammalian target of rapamycin complex 1 (mTORC1), $\operatorname{PPAR} \alpha$ signalling and placental nutrient transport ${ }^{(125)}$. Adiponectin also mediates the crosstalk between AT and the vessel wall; thus, in virtue of its pleiotropic activities on multiple targets, it seems to have a protective role against vascular dysfunction induced by obesity and diabetes ${ }^{(126)}$.
TNF $\alpha$ and leptin have been suggested as the strongest predictors of pregnancy-related $\mathrm{IR}^{(127,128)}$. Hyperleptinaemia in early pregnancy (13 weeks) appears to be a good predictor of GDM risk, independent of maternal adiposity ${ }^{(129,130)}$. In week 30 of pregnancy, leptin levels have been found to be similar in both GDM and no-GDM subjects, but they remained elevated after delivery in the GDM group ${ }^{(131)}$.

Recent systematic reviews have highlighted higher and lower levels of plasma leptin and adiponectin, respectively, in the first or second trimester of pregnancy ${ }^{(132)}$, and this condition persisted, associated also with high TNF- $\alpha$ levels, in the late second or third trimester of pregnancy ${ }^{(133)}$, in GDM patients compared with normal pregnancies. These findings corroborate the role exerted by the altered balance pro-inflammatory/anti-inflammatory factors in the impaired glucose homoeostasis in GDM.

Increased levels of leptin have been found in visceral AT of obese and GDM women ${ }^{(109)}$. Leptin, predominantly produced by adipocytes, is considered an essential factor in maintaining energy homoeostasis, as it regulates food intake and energy expenditure via specific receptors in the hypothalamus ${ }^{(134)}$. Leptin acts by activating Janus kinase/signal transducer and activator of transcription signalling, although other important intracellular signalling including PI3K, AMPK and MAPK appear to be involved as well ${ }^{(134)}$.

In GDM women, TNF $\alpha$ and leptin levels are elevated; the increased $\mathrm{TNF} \alpha$ expression causes a chronic inflammatory environment with enhanced leptin production, which, in turn, increases TNF $\alpha$ and IL-6 production by monocytes ${ }^{(135)}$, generating a vicious circle that amplifies the inflammatory situation and worsens the metabolic dysfunction in GDM. Although the significance of leptin and adiponectin is relatively well characterised as for their effects on glucose and lipid metabolism in diabetes, the molecular mechanisms by which these adipokines exert their effects on insulin action are not completely defined. Much more research is needed especially in the light of the growing list of molecules identified as adipokines, for example, visfatin, apelin, retinol-binding protein 4 , vaspin, omentin and adiposity FA-binding protein 4 (FABP4), which renders the comprehension of the existing network and the interactions among them more complicated ${ }^{(9,136,137)}$

\section{Polyphenols effects}

The beneficial effects of MedDiet dietary compounds on diabetes are associated with reduced biomarkers of inflammation ${ }^{(138-140)}$.

Taking into account the importance of the insulin-sensitising effects of adiponectin, enhancing adiponectin/AdipoR function may be an interesting therapeutic strategy against IR ${ }^{(141)}$. Dietary compounds such as fish oil, linoleic acid (LA), seed extract, green tea extract and resveratrol (RSV) elevated adiponectin concentration; specifically, RSV $(50 \mu \mathrm{m}$ for $24 \mathrm{~h})$ treatment stimulated adiponectin expression and reduced mRNA levels of leptin in 3T3-L1 adipocytes ${ }^{(142,143)}$. The stimulatory effect of RSV has been shown to be mediated via histone deacetylase sirtuin 1 (Sirt-1)-independent mechanism and is mainly because of phosphoinositide-dependent protein kinase-1/Akt signalling pathway suppression, in the activation of the transcription factor forkhead box O-1 (FOXO1), and the AMPK signalling 
pathway $^{(142)}$. RSV $(0 \cdot 1-10 \mu \mathrm{M})$ reduced the expression and release of IL- 6 and TNF $\alpha$ in RAW 264.7 macrophages and 3T3-L1 cells, in association with a reduced extracellular signal-regulated protein kinases $1 / 2(E R K 1 / 2)$ and NF- $\kappa \mathrm{B}$ activation $^{(144)}$. The high-glucose-induced nitric oxide (NO) reduction was reverted by RSV $(0 \cdot 1-10 \mu \mathrm{m}$ for $24 \mathrm{~h})$ incubation in bovine artery endothelial cells, because of enhanced endothelial NO synthase mRNA and activity ${ }^{(145)}$. Altogether, these findings strongly indicate that RSV could be a therapeutic supplement to counteract the diabetic condition.

C3G treatment $(12 \cdot 5,25,50 \mu \mathrm{m}$ for $24 \mathrm{~h})$ induced adiponectin expression in 3T3-L1 and human adipocytes ${ }^{(98,146)}$. As regards the molecular mechanisms, C3G induced FOXO1 deacetylation and transcriptional activity, as well as increased PPAR $\gamma$ activity ${ }^{(98)}$, which, in turn, brought about adiponectin expression and secretion, in adipocytes ${ }^{(146)}$. In addition, flavonoid fisetin $(0 \cdot 1-10 \mu \mathrm{m}$ for $24 \mathrm{~h})$ increased adiponectin gene transcription by inducing SIRT-1-deacetylase activity and PPAR activation, in mouse adipocytes ${ }^{(147,148)}$.

Virgin olive oil components such as hydroxytyrosol (HT; $0 \cdot 1-20 \mu \mathrm{M}$ for $1 \mathrm{~h}$ pretreatment) and oleic acid (100 $\mu \mathrm{m}$ for $48 \mathrm{~h}$ pretreatment) alone or in combination in human adipocytes can prevent TNF $\alpha$-induced down-regulation of adiponectin by attenuating PPAR $\gamma$ suppression mediated by c-Jun $N$-terminal kinase (JNK) ${ }^{(149)}$. Moreover, HT, oleuropein, taxifolin and tyrosol ( $50 \mu \mathrm{m}$ pretreatment for $24 \mathrm{~h}$ each) showed anti-angiogenesis activities as well ${ }^{(150)}$. Indeed, all these compounds suppressed angiogenesis in human umbilical vein endothelial cells by inhibiting vascular endothelial growth factor receptor 2 (VEGFR-2) signalling pathway. Specifically, HT and taxifolin inhibited VEGF-dependent tyrosine phosphorylation of VEGFR-2 by impairing phosphorylation of p42/p44 MAPK (ERK1/2) and p46/p54 stress-activated protein kinase (SAPK)/ $\mathrm{JNK}^{(150)}$. Altogether, these data provide further molecular evidence of the beneficial effects of olive oil consumption in the MedDiet in the treatment of metabolic diseases.

The soya isoflavones and their aglycones daidzein and genistein, as well as the equol metabolite ( $40 \mu \mathrm{m}$ for $2 \mathrm{~h}$ for each), inhibited leptin secretion in mouse adipocytes ${ }^{(151)}$. A mechanistic study carried out in 3T3-L1 adipocytes demonstrated that genistein and daidzein inhibit TNF $\alpha$-mediated down-regulation of adiponectin through different mechanisms; genistein inhibited TNF $\alpha$-induced JNK signalling and daidzein inhibited TNF $\alpha$-induced down-regulation of FOXO1 ${ }^{(152)}$. Naringin $(80 \mu \mathrm{M}$ pretreatment for $2 \mathrm{~h}$ ) incubation down-regulated the highglucose-induced leptin expression and inhibited leptin-induced activation of the p38 MAPK pathway in H9c2 cardiac cells ${ }^{(153)}$. An in vivo study showed that oral administration of naringin $(50 \mathrm{mg} / \mathrm{kg}$ for 4 weeks) or hesperidin $(50 \mathrm{mg} / \mathrm{kg}$ for 4 weeks $)$ in diabetic rats significantly reduced the percentage of blood glycated $\mathrm{Hb}$, and serum levels of TNF $\alpha$ and IL- $6^{(154)}$. In humans, purified anthocyanin $(320 \mathrm{mg} / \mathrm{d}$ for 12 weeks) supplementation significantly increased serum adiponectin concentrations in patients with $\mathrm{T} 2 \mathrm{D}^{(146)}$.

The metabolites of polyphenols can be useful biomarkers of dietary intake to evaluate individual response to specific compounds; for example, equol is not produced in all adults who consume soya foods ${ }^{(155)}$. A recent study has shown that, in pre- diabetic and diabetic female population, the 'equol producers' subjects exhibited lower levels of leptin as compared with nonproducers, indicating an association between isoflavone intake and leptin levels ${ }^{(155)}$. In healthy obese postmenopausal women, physical activity, diet and daily oral intake of a soya isoflavone extract $(60.8 \mathrm{mg}$ of genistein, $16 \mathrm{mg}$ of daidzein and $3.2 \mathrm{mg}$ of glycitein) resulted in reduced levels of serum leptin and TNF $\alpha$ associated with a significant increase in adiponectin, after 6 months of treatment ${ }^{(156)}$

A recent and exhaustive review describes the inhibitory effects of certain polyphenols on TNF $\alpha$-activated inflammatory pathways both in vitro and in vivo, and in human studies ${ }^{(157)}$.

\section{The health effects of PUFA}

A substantial amount of FA is required as additional source of energy to support fetal cellular growth, and gestational hyperlipidaemia normally occurring during late pregnancy enhances placental access to $\mathrm{FA}^{(158,159)}$. GDM associates with an altered maternal lipid profile and affects the quantity and/or quality of lipids transferred to the fetus ${ }^{(160)}$. In GDM, a positive correlation between maternal TAG and NEFA levels, and fetal growth and fat mass, has been found even in diabetic mothers with appropriate glycaemic control ${ }^{(160)}$. Fetus development depends on the maternal supply of essential PUFA such as LA (18:2 n-6), $\alpha$-linolenic acid (ALA, 18:3n-3) and long-chain (LC)-PUFA, EPA (20:5n-3), DHA (22:6n-3) and arachidonic acid (AA, $20: 4 n-6)^{(161)}$. The placenta regulates adequate LC-PUFA delivery to the fetus in a directional, preferential and timely manner ${ }^{(161)}$, preferentially transferring $n-3$ LC-PUFA $^{(159)}$. In GDM women, the placental transfer of LC-PUFA appears to be altered, with an impaired maternal-fetal transfer of DHA, which might affect neurodevelopment programming in the offspring ${ }^{(162)}$. A reduced concentration of LC-PUFA in maternal, placental and fetal compartments in GDM women compared with healthy pregnant women has been highlighted ${ }^{(163,164)}$.

However, increased, unchanged or lower hyperlipidaemia in diabetic pregnant women $v$. non-diabetic pregnant women has been observed too ${ }^{(160)}$. In this regard, it has been hypothesised that the degree of metabolic control and sex hormonal dysfunction may influence the different degree of dyslipidaemia observed in diabetic pregnant women ${ }^{(160)}$. NEFA are taken up by the placenta and FA are released from maternal lipoproteins by endothelial lipase (EL) and lipoprotein lipase (LPL), which are present in the maternal-facing microvillus membrane of the syncytiotrophoblast ${ }^{(162)}$. Increased EL mRNA has been found in placenta from obese women with GDM compared with lean GDM women or normoglycemic pregnant women ${ }^{(165)}$. In contrast, a recent study has shown that no difference in the expression of LPL and EL exists between GDM and normoglycaemic placentas, suggesting that these lipases are not involved in the increased newborn adiposity ${ }^{(166)}$. NEFA may enter the cell by passive diffusion or by several plasma membranelocated transport/binding proteins including FA translocase (FAT/CD36), plasma membrane FABP(pm), FA transport proteins (FATP1-6) and intracellular FABP ${ }^{(167)}$. DHA and EPA are endogenous ligands of several transcription factors such as PPAR, RXR and SREBP1 ${ }^{(168)}$. A decreased expression of genes 
involved in FA uptake, intracellular transport, storage and synthesis (e.g. LPL, FATP2, FATP6, FABPpm, acyl-CoA synthetase long-chain family member 1 ), and of transcription factors involved in lipid metabolism regulation (e.g. liver $X$ receptor $(L X R \alpha)$, PPAR, PPAR, PPAR $, R X R \alpha, S R E B P 1 c)$, has been observed in AT obtained from obese pregnant women and women with $\mathrm{GDM}^{(109)}$. These results indicate that pre-existing maternal obesity and GDM are associated with abnormal AT lipid metabolism, which may play a role in the pathogenesis of both diseases ${ }^{(109)}$.

\section{Dietary effects}

PUFA are fundamental for human beings, and particularly important is the balance of $n-6: n-3$ FA in maintaining homoeostasis, normal development and mental health throughout the lifecycle ${ }^{(161)}$. Different studies have led to the conclusion that humans currently need a diet containing $n-3$ and $n-6$ PUFA in a ratio of about 1:5; on the contrary, in Western diets, this ratio is 1:10-20, indicating a deficiency in $n-3 \mathrm{FA}$ and/or an excess of $n-6 \mathrm{FA}^{(169)}$. The essential FA, LA and ALA cannot be synthesised by humans and therefore must be supplied through the diet; a series of sequential desaturation and elongation reactions acting in concert transform LA and ALA into their unsaturated derivatives, namely AA from LA, EPA and DHA from ALA ${ }^{(170)}$. EPA and DHA are abundantly present in specific fishes, for example, fresh tuna, salmon and mackerel, as well as in fish oil and nuts ${ }^{(171,172)}$. Nuts, vegetables, vegetable oils, for example, soyabean, flaxseed and rapeseed oil, and cereals are also food sources of ALA and LA ${ }^{(49,170)}$. Walnuts are widely consumed in Mediterranean regions and are rich in ALA $(2.95 \mathrm{~g} / 28.4 \mathrm{~g})^{(173)}$. In the PREDIMED (PREvención con DIeta MEDiterránea) trial that involved subjects at high risk for CVD, a diet rich in fats of vegetable origin, olive oil and mixed nuts $(30 \mathrm{~g} / \mathrm{d}$, as $15 \mathrm{~g}$ walnuts, $7.5 \mathrm{~g}$ hazelnuts and $7.5 \mathrm{~g}$ almonds) has been shown to be beneficial in the management of the metabolic syndrome ${ }^{(174)}$. The fat content of vegetables is low, but a high consumption of vegetables will result in a substantial intake of ALA. The content of ALA in some edible plants growing in the Mediterranean regions is remarkable, as in the case with purslane (300-400 mg ALA/100 g) $)^{(175,176)}$.

Different cohort studies have shown a positive association between the adherence to MedDiet style, and plasma DHA and EPA content, indicating that the MedDiet ensures higher $n$-3 PUFA bioavailability than Western diets ${ }^{(177-180)}$.

The European Commission and the International Society for the Study of Fatty Acids and Lipids specifically recommend that pregnant and lactating women consume a minimum of $200 \mathrm{mg}$ $\mathrm{DHA} / \mathrm{d}^{(181)}$. Several researches indicate that maternal dietary supplementation with $n$-3 PUFA during pregnancy can reduce the risk of pregnancy complications by limiting placental inflammation and oxidative stress ${ }^{(159,182,183)}$, with positive action on insulin function, improvement of glucose tolerance and lipid profiles ${ }^{(184,185)}$ (Table 2).

A daily dose of $600 \mathrm{mg}$ of DHA, starting from the first trimester until delivery, can ameliorate red cell membrane anomaly in pregnant women with T2D and in neonates, and it prevents the decline of maternal DHA during pregnancy ${ }^{(186)}$. These results suggest that DHA supplementation should be started in

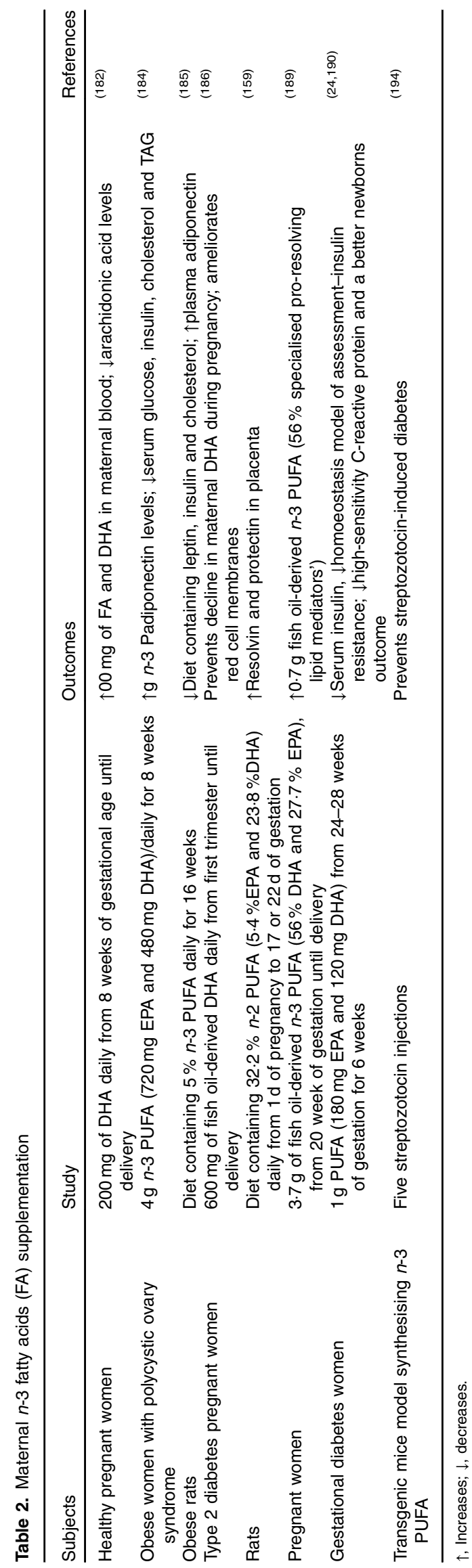


the antenatal care of pregnant women with T2D. An Italian pilot study revealed that daily administration of $200 \mathrm{mg}$ of DHA, from the 8th week until delivery, reduced AA levels in erythrocytes and plasma during gestational time ${ }^{(182)}$. Thus, the increased DHA levels in the maternal plasma and the consequent reduction of AA-derived eicosanoids decrease inflammation, with a beneficial effect on fetal development and growth, and IR of amniochorial membranes as well ${ }^{(182)}$. New identified PUFA-derived mediators (specialised pro-resolving lipid mediators), namely resolvins, protectins, maresins and lipoxins, are involved in inflammatory resolution ${ }^{(187)}$. It has been observed that maternal dietary supplementation with $n-3$ PUFA might help placenta in resolving inflammation by increasing the levels of these pro-resolving mediators, in rat ${ }^{(188)}$ and in human placenta $^{(189)}$. GDM women who received $1000 \mathrm{mg} / \mathrm{d} n$-3 FA supplementation (containing $180 \mathrm{mg}$ of EPA and $120 \mathrm{mg}$ of DHA) for 6 weeks, starting in weeks 24-28 of gestation, showed a significant decrease in serum insulin levels and in HOMA index (homoeostasis model of assessment-IR) ${ }^{(24)}$, highsensitivity C-reactive protein (CRP) and better newborn outcome ${ }^{(190)}$, compared with placebo groups.

The need of higher PUFA intake in pregnancy is highlighted by data collected from 600 women participating in the Alberta Pregnancy Outcomes and Nutrition study ${ }^{(191)}$. Through the development of a dietary database for $n$ - 3 PUFA, the authors evaluated PUFA intake each trimester of pregnancy and 3 months postpartum: results indicate that the majority of women did not meet the European Union recommendation for DHA during pregnancy ${ }^{(191)}$.

The mechanism through which $n$-3 FA intake might influence insulin metabolism is not well known. It has been hypothesised that $n$-3 PUFA supplementation might affect insulin metabolism and lipid profiles by activating $\mathrm{AMPK}^{(192)}$. In agreement with this finding, a recent study showed that RSV supplementation, before, and throughout, pregnancy increased placental DHA uptake capacity in pregnant non-human primates fed a high-fat diet (i.e. $36 \%$ fat supplemented with $0.37 \%$ RSV $)^{(193)}$. This effect was associated with increased AMPK activity and FATP-4, CD36 and FABPPm mRNA expression ${ }^{(193)}$. In addition, $n-3$ PUFA might modulate gene expression through a variety of transcription factors with tissue-specific effects; $n$-3 PUFA improve insulin metabolism by inhibiting pro-inflammatory cytokine release and $\mathrm{NF}-\kappa \mathrm{B}$ protein expression $^{(194)}$, and by activating their G-protein-coupled receptor $120^{(195)}$.

A recent meta-analysis showed that long-term supplementation of marine-derived $n-3$ PUFA results in a significant reduction of IL-6, TNF $\alpha$ and CRP plasma levels, in both healthy and non-healthy subjects ${ }^{(196)}$.

Moreover, the increasing vegetarian and vegan population requires alternative sources of LC-PUFA to guarantee them the appropriate intake of $n-3 \mathrm{FA}^{(30,197,198)}$. In addition to eating a larger quantity of vegetables, with a higher content of essential $n-3$ FA, a promising source of $n-3$ PUFA is represented by different species of microalgae ${ }^{(199,200)}$. To this purpose, the European Commission has authorised the use in certain foods of oil derived from microalgae Schizochytrium sp. rich in DHA and EPA (EU decision no. 2015/545 and no. 2015/546),
Altogether, these data provide useful scientific information for planning future investigations aimed at exploring PUFA effects when considering a nutritional therapy of inflammatory diseases and GDM.

\section{Conclusions and future research}

GDM is increasing worldwide; obesity worsens this condition with increased risk of developing metabolic disorders in both mother and offspring later in life. The adoption of healthy lifestyle, with the adherence to a healthy dietary pattern, has positive effects on the prevention and management of diabetes. The Mediterranean diet is considered the model of healthy diet, and even more studies demonstrate its power in reducing the burden of several disorders in human being.

The few studies investigating the impact of healthy diet on GDM indicate that adherence to a healthy dietary pattern before pregnancy can reduce the risk of developing GDM; very few data about the association between dietary exposure and GDM outcomes are available.

Accordingly, this descriptive review tried to provide a picture on what we know about the impact of specific dietary biocompounds (i.e. polyphenols and PUFA) on the molecular mechanisms involved in glucose homoeostasis. Literature data, mostly derived from in vitro or animals studies, indicate that almost all subclasses of flavonoids, as well as the stilbene RSV and some olive oil phenolic compounds, interact and modulate several molecular pathways regulating insulin sensitivity in pancreatic $\beta$-cell, adipocyte, liver and muscle. Polyphenols drive activation and/ or silencing of transcription factors and consequently influence genes expression. Moreover, the fact that miRNA are the target of polyphenols action is to be taken into account in the future studies aimed at improving the understanding of the biological effects of polyphenols. However, how these compounds might work in GDM setting is a matter of speculation. Although increasing data indicate the beneficial effect of PUFA on pregnancy, a high-level evidence has not yet been achieved to make recommendations for GDM.

Many gaps, in the nutritional field and in the knowledge of pathophysiological processes, have to be filled in to progress in GDM prevention and management. GDM results from a complex interaction between the genetic background and environment. Identifying a number of modifiable biomarkers (including adipokines and miRNA) and the nutritional factors (e.g. polyphenols and their metabolites) able to target them can be useful in both early diagnosis and disease management.

It will be necessary to carry out dietary intervention studies involving large cohorts, and take into account genetic and dietary differences among races and countries. The 'omics' techniques will be fundamental tools to monitor dietary changes in populations and to identify the association between dietary exposure and disease outcomes. The integration of data from an individual's genetic predisposition, endogenous metabolome, food metabolome and mirRNome profiles by systems biology approaches will provide a holistic view (systems biology approaches) of the relations between diet and disease, and will make it possible to translate these data in nutritional recommendations and diseases management. In particular, 
differences in metabolic profiles will be useful to identify novel biomarkers of dietary intake associated with disease. In this regard, the recent creation of a database to estimate intake and dietary seafood source of LC-PUFA in pregnancy provides a useful tool and represents an important step for future intervention studies.

Sharing this database along with others providing information on dietary polyphenols and polyphenol metabolites will help researchers to better understand the mechanisms governing interaction between dietary active compounds and the human organism.

\section{Acknowledgements}

The authors thank Monica Brocco for the linguistic revision.

This research received no specific grant from any funding agency, commercial or not-for-profit sectors.

C. S., R. M., A. Z. and S. M. contributed to the idea and development of the research. E. Mandosi, B. S. and E. Mari assisted with literature review and data collection. C. S., R. M., A. Z. and S. M. developed the first draft of the paper. All authors reviewed multiple drafts of the paper and approved the final manuscript for submission.

The authors declare that there are no conflicts of interest.

\section{References}

1. Chen P, Wang S, Ji J, et al. (2015) Risk factors and management of gestational diabetes. Cell Biochem Biophys 71, 689-694.

2. Yuen L \& Wong VW (2015) Gestational diabetes mellitus: challenges for different ethnic groups. World J Diabetes $\mathbf{6}$, 1024-1032.

3. Bao W, Yeung E, Tobias DK, et al. (2015) Long-term risk of type 2 diabetes mellitus in relation to BMI and weight change among women with a history of gestational diabetes mellitus: a prospective cohort study. Diabetologia 58, 1212-1219.

4. Harris DL, Weston PJ \& Harding JE (2012) Incidence of neonatal hypoglycemia in babies identified as at risk. J Pediatr 161, 787-791.

5. Yessoufou A \& Moutairou K (2011) Maternal diabetes in pregnancy: early and long-term outcomes on the offspring and the concept of 'metabolic memory'. Exp Diabetes Res 2011, 218598.

6. Benhalima K, Mathieu C, Damm P, et al. (2015) A proposal for the use of uniform diagnostic criteria for gestational diabetes in Europe: an opinion paper by the European Board \& College of Obstetrics and Gynaecology (EBCOG). Diabetologia 58, 1422-1429.

7. Agarwal MM (2015) Gestational diabetes mellitus: an update on the current international diagnostic criteria. World $J$ Diabetes 6, 782-791.

8. Sacks DA, Hadden DR, Maresh M, et al. (2012) Frequency of gestational diabetes mellitus at collaborating centers based on IADPSG consensus panel-recommended criteria: the Hyperglycemia and Adverse Pregnancy Outcome (HAPO) Study. Diabetes Care 35, 526-528.

9. Santangelo C, Vari R, Scazzocchio B, et al. (2014) Management of reproduction and pregnancy complications in maternal obesity: which role for dietary polyphenols? Biofactors 40, 79-102.
10. Georgoulis M, Kontogianni MD \& Yiannakouris N (2014) Mediterranean diet and diabetes: prevention and treatment. Nutrients 6, 1406-1423.

11. Sofi F, Macchi C, Abbate R, et al. (2014) Mediterranean diet and health status: an updated meta-analysis and a proposal for a literature-based adherence score. Public Health Nutr 17, 2769-2782.

12. Capurso C, Massaro M, Scoditti E, et al. (2014) Vascular effects of the Mediterranean diet part I: anti-hypertensive and anti-thrombotic effects. Vascul Pharmacol 63, 118-126.

13. Esposito K, Maiorino MI, Bellastella G, et al. (2015) A journey into a Mediterranean diet and type 2 diabetes: a systematic review with meta-analyses. BMJ Open 5, e008222.

14. Bonaccio M, Di Castelnuovo A, Costanzo S, et al. (2015) Adherence to the traditional Mediterranean diet and mortality in subjects with diabetes. Prospective results from the MOLI-SANI study. Eur J Prev Cardiol (epublication ahead of print version 3 February 2015).

15. Koloverou E, Panagiotakos DB, Pitsavos C, et al. (2016) Adherence to Mediterranean diet and 10-year incidence (2002-2012) of diabetes: correlations with inflammatory and oxidative stress biomarkers in the ATTICA cohort study. Diabetes Metab Res Rev 32, 73-81.

16. Yang J, Farioli A, Korre M, et al. (2014) Modified Mediterranean diet score and cardiovascular risk in a North American working population. PLOS ONE 9, e87539.

17. Steffen LM, Van Horn L, Daviglus ML, et al. (2014) A modified Mediterranean diet score is associated with a lower risk of incident metabolic syndrome over 25 years among young adults: the CARDIA (Coronary Artery Risk Development in Young Adults) study. Br J Nutr 112, 1654-1661.

18. Hoscan Y, Yigit F \& Muderrisoglu H (2015) Adherence to Mediterranean diet and its relation with cardiovascular diseases in Turkish population. Int J Clin Exp Med 8, 2860-2866

19. Grosso G, Stepaniak U, Micek A, et al. (2015) A Mediterranean-type diet is associated with better metabolic profile in urban Polish adults: results from the HAPIEE study. Metabolism 64, 738-746.

20. Asemi Z, Samimi M, Tabassi Z, et al. (2014) The effect of DASH diet on pregnancy outcomes in gestational diabetes: a randomized controlled clinical trial. Eur J Clin Nutr 68 , 490-495.

21. Tobias DK, Zhang C, Chavarro J, et al. (2012) Prepregnancy adherence to dietary patterns and lower risk of gestational diabetes mellitus. Am J Clin Nutr 96, 289-295.

22. Karamanos B, Thanopoulou A, Anastasiou E, et al. (2014) Relation of the Mediterranean diet with the incidence of gestational diabetes. Eur J Clin Nutr 68, 8-13.

23. Salas-Salvado J, Martinez-Gonzalez MA, Bullo M, et al. (2011) The role of diet in the prevention of type 2 diabetes. Nutr Metab Cardiovasc Dis 21, Suppl. 2, B32-B48.

24. Samimi M, Jamilian M, Asemi Z, et al. (2015) Effects of omega-3 fatty acid supplementation on insulin metabolism and lipid profiles in gestational diabetes: randomized, double-blind, placebo-controlled trial. Clin Nutr 34, 388-393.

25. Wang H, Jiang H, Yang L, et al. (2015) Impacts of dietary fat changes on pregnant women with gestational diabetes mellitus: a randomized controlled study. Asia Pac J Clin Nutr 24, 58-64.

26. Mirmiran P, Bahadoran Z \& Azizi F (2014) Functional foodsbased diet as a novel dietary approach for management of type 2 diabetes and its complications: a review. World $J$ Diabetes 5, 267-281. 
27. Xiao JB \& Hogger P (2015) Dietary polyphenols and type 2 diabetes: current insights and future perspectives. Curr Med Chem 22, 23-38.

28. Bahadoran Z, Mirmiran P \& Azizi F (2013) Dietary polyphenols as potential nutraceuticals in management of diabetes: a review. J Diabetes Metab Disord 12, 43.

29. Oh YS \& Jun HS (2014) Role of bioactive food components in diabetes prevention: effects on beta-cell function and preservation. Nutr Metab Insights 7, 51-59.

30. Saunders AV, Davis BC \& Garg ML (2013) Omega-3 polyunsaturated fatty acids and vegetarian diets. Med J Aust 199, S22-S26.

31. Trichopoulou A, Bamia C \& Trichopoulos D (2009) Anatomy of health effects of Mediterranean diet: Greek EPIC prospective cohort study. BMJ 338, b2337.

32. Bravo L (1998) Polyphenols: chemistry, dietary sources, metabolism, and nutritional significance. Nutr Rev 56, 317-333.

33. Scalbert A, Manach C, Morand C, et al. (2005) Dietary polyphenols and the prevention of diseases. Crit Rev Food Sci Nutr 45, 287-306.

34. Neveu V, Perez-Jimenez J, Vos F, et al. (2010) PhenolExplorer: an online comprehensive database on polyphenol contents in foods. Database (Oxford) 2010, bap024.

35. Manach C, Scalbert A, Morand C, et al. (2004) Polyphenols: food sources and bioavailability. Am J Clin Nutr 79, 727-747.

36. Perez-Jimenez J, Fezeu L, Touvier M, et al. (2011) Dietary intake of 337 polyphenols in French adults. Am J Clin Nutr 93, 1220-1228.

37. Tsao R (2010) Chemistry and biochemistry of dietary polyphenols. Nutrients 2, 1231-1246.

38. Landete JM (2012) Updated knowledge about polyphenols: functions, bioavailability, metabolism, and health. Cri Rev Food Sci Nutr 52, 936-948.

39. Del Rio D, Costa LG, Lean ME, et al. (2010) Polyphenols and health: what compounds are involved? Nutr Metab Cardiovasc Dis 20, 1-6.

40. Lancon A, Michaille JJ \& Latruffe N (2013) Effects of dietary phytophenols on the expression of microRNAs involved in mammalian cell homeostasis. J Sci Food Agric 93, 3155-3164.

41. Santangelo C, Vari R, Scazzocchio B, et al. (2007) Polyphenols, intracellular signalling and inflammation. Ann Ist Super Sanita 43, 394-405.

42. Sebastian RS, Wilkinson Enns C, Goldman JD, et al. (2015) A new database facilitates characterization of flavonoid intake, sources, and positive associations with diet quality among US adults. J Nutr 145, 1239-1248.

43. Zamora-Ros R, Forouhi NG, Sharp SJ, et al. (2014) Dietary intakes of individual flavanols and flavonols are inversely associated with incident type 2 diabetes in European populations. J Nutr 144, 335-343.

44. D'Archivio M, Filesi C, Vari R, et al. (2010) Bioavailability of the polyphenols: status and controversies. Int J Mol Sci 11, 1321-1342.

45. Fraga CG, Galleano M, Verstraeten SV, et al. (2010) Basic biochemical mechanisms behind the health benefits of polyphenols. Mol Aspects Med 31, 435-445.

46. Monteagudo C, Mariscal-Arcas M, Rivas A, et al. (2015) Proposal of a Mediterranean Diet Serving Score. PLOS ONE 10, e0128594.

47. Gonzalez S, Fernandez M, Cuervo A, et al. (2014) Dietary intake of polyphenols and major food sources in an institutionalised elderly population. J Hum Nutr Diet 27, $176-183$.
48. Murphy MM, Barraj LM, Spungen JH, et al. (2014) Global assessment of select phytonutrient intakes by level of fruit and vegetable consumption. Br J Nutr 112, 1004-1018.

49. United States Department of Agriculture (USDA) Agricultural Research Service (ARS) (2012) Nutrient Data Laboratory USDA National Nutrient Database for Standard reference. http:// www.nal.usda.gov/fnic/foodcomp/search

50. Wang J, Tang L \& Wang JS (2015) Biomarkers of dietary polyphenols in cancer studies: current evidence and beyond. Oxid Med Cell Longev 2015, 732302.

51. Edmands WM, Ferrari P, Rothwell JA, et al. (2015) Polyphenol metabolome in human urine and its association with intake of polyphenol-rich foods across European countries. Am J Clin Nutr 102, 905-913.

52. Scalbert A, Brennan L, Manach C, et al. (2014) The food metabolome: a window over dietary exposure. Am J Clin Nutr 99, 1286-1308.

53. Sonagra AD, Biradar SM, K D, et al. (2014) Normal pregnancy - a state of insulin resistance. J Clin Diagn Res $\mathbf{8}$, CC01-CC03.

54. Catalano PM, Huston L, Amini SB, et al. (1999) Longitudinal changes in glucose metabolism during pregnancy in obese women with normal glucose tolerance and gestational diabetes mellitus. Am J Obstet Gynecol 180, 903-916.

55. Harlev A \& Wiznitzer A (2010) New insights on glucose pathophysiology in gestational diabetes and insulin resistance. Curr Diab Rep 10, 242-247.

56. Catalano PM (2014) Trying to understand gestational diabetes. Diabet Med 31, 273-281.

57. Friedman JE, Ishizuka T, Shao J, et al. (1999) Impaired glucose transport and insulin receptor tyrosine phosphorylation in skeletal muscle from obese women with gestational diabetes. Diabetes 48, 1807-1814.

58. Tersigni C, Di Nicuolo F, D'Ippolito S, et al. (2011) Adipokines: new emerging roles in fertility and reproduction. Obstet Gynecol Surv 66, 47-63.

59. Li N, Liu E, Guo J, et al. (2013) Maternal prepregnancy body mass index and gestational weight gain on pregnancy outcomes. PLOS ONE 8, e82310.

60. Lappas M (2014) Activation of inflammasomes in adipose tissue of women with gestational diabetes. Mol Cell Endocrinol 382, 74-83.

61. Krutzfeldt J \& Stoffel M (2006) MicroRNAs: a new class of regulatory genes affecting metabolism. Cell Metab 4, 9-12.

62. Mao Y, Mohan R, Zhang S, et al. (2013) MicroRNAs as pharmacological targets in diabetes. Pharmacol Res $\mathbf{7 5}$, $37-47$.

63. Guay C, Roggli E, Nesca V, et al. (2011) Diabetes mellitus, a microRNA-related disease? Trans Res 157, 253-264.

64. Lynn FC (2009) Meta-regulation: microRNA regulation of glucose and lipid metabolism. Trends Endocrinol Metab 20, 452-459.

65. Chen H, Lan HY, Roukos DH, et al. (2014) Application of microRNAs in diabetes mellitus. $J$ Endocrinol 222, R1-R10.

66. Dweep H \& Gretz N (2015) miRWalk2.0: a comprehensive atlas of microRNA-target interactions. Nat Methods 12, 697.

67. Collares CV, Evangelista AF, Xavier DJ, et al. (2013) Identifying common and specific microRNAs expressed in peripheral blood mononuclear cell of type 1, type 2, and gestational diabetes mellitus patients. BMC Res Notes 6, 491.

68. Fu G, Brkic J, Hayder H, et al. (2013) MicroRNAs in human placental development and pregnancy complications. Int $J$ Mol Sci 14, 5519-5544.

69. Zhao C, Dong J, Jiang T, et al. (2011) Early second-trimester serum miRNA profiling predicts gestational diabetes mellitus. PLOS ONE 6, e23925. 
70. Zhu Y, Tian F, Li H, et al. (2015) Profiling maternal plasma microRNA expression in early pregnancy to predict gestational diabetes mellitus. Int J Gynaecol Obstet 130, 49-53.

71. Etheridge A, Lee I, Hood L, et al. (2011) Extracellular microRNA: a new source of biomarkers. Mutat Res $\mathbf{7 1 7}$, 85-90.

72. He A, Zhu L, Gupta N, et al. (2007) Overexpression of micro ribonucleic acid 29, highly up-regulated in diabetic rats, leads to insulin resistance in 3T3-L1 adipocytes. Mol Endocrinol 21, 2785-2794.

73. Yang WM, Jeong HJ, Park SY, et al. (2014) Induction of miR-29a by saturated fatty acids impairs insulin signaling and glucose uptake through translational repression of IRS-1 in myocytes. FEBS Lett 588, 2170-2176.

74. Bagge A, Clausen TR, Larsen S, et al. (2012) MicroRNA-29a is up-regulated in beta-cells by glucose and decreases glucosestimulated insulin secretion. Biochem Biophys Res Commun 426, 266-272.

75. Nesca V, Guay C, Jacovetti C, et al. (2013) Identification of particular groups of microRNAs that positively or negatively impact on beta cell function in obese models of type 2 diabetes. Diabetologia 56, 2203-2212.

76. Shi Z, Zhao C, Guo X, et al. (2014) Differential expression of microRNAs in omental adipose tissue from gestational diabetes mellitus subjects reveals miR-222 as a regulator of ERalpha expression in estrogen-induced insulin resistance. Endocrinology 155, 1982-1990.

77. Zhou B, Li C, Qi W, et al. (2012) Downregulation of miR-181a upregulates sirtuin-1 (SIRT1) and improves hepatic insulin sensitivity. Diabetologia 55, 2032-2043.

78. Arola-Arnal A \& Blade C (2011) Proanthocyanidins modulate microRNA expression in human HepG2 cells. PLOS ONE $\mathbf{6}$, e25982.

79. Bridge G, Monteiro R, Henderson S, et al. (2012) The microRNA-30 family targets DLL4 to modulate endothelial cell behavior during angiogenesis. Blood 120, 5063-5072.

80. Pietro L, Daher S, Rudge MV, et al. (2010) Vascular endothelial growth factor (VEGF) and VEGF-receptor expression in placenta of hyperglycemic pregnant women. Placenta 31, 770-780.

81. Joglekar MV, Patil D, Joglekar VM, et al. (2009) The miR-30 family microRNAs confer epithelial phenotype to human pancreatic cells. Islets 1, 137-147.

82. Zhang C, Tobias DK, Chavarro JE, et al. (2014) Adherence to healthy lifestyle and risk of gestational diabetes mellitus: prospective cohort study. BMJ 349, g5450.

83. Hanhineva K, Torronen R, Bondia-Pons I, et al. (2010) Impact of dietary polyphenols on carbohydrate metabolism. Int J Mol Sci 11, 1365-1402.

84. Berna G, Oliveras-Lopez MJ, Jurado-Ruiz E, et al. (2014) Nutrigenetics and nutrigenomics insights into diabetes etiopathogenesis. Nutrients 6, 5338-5369.

85. Babu PV, Liu D \& Gilbert ER (2013) Recent advances in understanding the anti-diabetic actions of dietary flavonoids. J Nutr Biochem 24, 1777-1789.

86. Garcia-Segura L, Perez-Andrade M \& Miranda-Rios J (2013) The emerging role of microRNAs in the regulation of gene expression by nutrients. J Nutrigenet Nutrigenomics $\mathbf{6}$, 16-31.

87. Palmer JD, Soule BP, Simone BA, et al. (2014) MicroRNA expression altered by diet: can food be medicinal? Ageing Res Rev 17, 16-24.

88. Milenkovic D, Jude B \& Morand C (2013) miRNA as molecular target of polyphenols underlying their biological effects. Free Radi Biol Med 64, 40-51.
89. Jimenez M, Dorado L, Hernandez-Perez M, et al. (2014) Ankle-brachial index in screening for asymptomatic carotid and intracranial atherosclerosis. Atherosclerosis 233, 72-75.

90. Crozier A, Jaganath IB \& Clifford MN (2009) Dietary phenolics: chemistry, bioavailability and effects on health. Nat Prod Rep 26, 1001-1043.

91. Fu Z \& Liu D (2009) Long-term exposure to genistein improves insulin secretory function of pancreatic beta-cells. Eur J Pharmacol 616, 321-327.

92. Cai EP \& Lin JK (2009) Epigallocatechin gallate (EGCG) and rutin suppress the glucotoxicity through activating IRS2 and AMPK signaling in rat pancreatic beta cells. J Agri Food Chem 57, 9817-9827.

93. Yu LF, Qiu BY, Nan FJ, et al. (2010) AMPK activators as novel therapeutics for type 2 diabetes. Curr Top Med Chem 10, 397-410.

94. Zhang ZF, Li Q, Liang J, et al. (2010) Epigallocatechin-3-Ogallate (EGCG) protects the insulin sensitivity in rat L6 muscle cells exposed to dexamethasone condition. Phytomedicine 17, 14-18.

95. Tsang WP \& Kwok TT (2010) Epigallocatechin gallate up-regulation of miR-16 and induction of apoptosis in human cancer cells. J Nutr Biochem 21, 140-146.

96. Takikawa M, Inoue S, Horio F, et al. (2010) Dietary anthocyanin-rich bilberry extract ameliorates hyperglycemia and insulin sensitivity via activation of AMP-activated protein kinase in diabetic mice. J Nutr 140, 527-533.

97. Sun CD, Zhang B, Zhang JK, et al. (2012) Cyanidin-3glucoside-rich extract from Chinese bayberry fruit protects pancreatic beta cells and ameliorates hyperglycemia in streptozotocin-induced diabetic mice. J Med Food 15, 288-298.

98. Scazzocchio B, Vari R, Filesi C, et al. (2011) Cyanidin-3-Obeta-glucoside and protocatechuic acid exert insulin-like effects by upregulating PPARgamma activity in human omental adipocytes. Diabetes 60, 2234-2244.

99. Masella R, Santangelo C, D'Archivio M, et al. (2012) Protocatechuic acid and human disease prevention: biological activities and molecular mechanisms. Curr Med Chem 19, 2901-2917.

100. Scazzocchio B, Vari R, Filesi C, et al. (2015) Protocatechuic acid activates key components of insulin signaling pathway mimicking insulin activity. Mol Nutr Food Res 59, 1472-1481.

101. Bhattacharya S, Oksbjerg N, Young JF, et al. (2014) Caffeic acid, naringenin and quercetin enhance glucose-stimulated insulin secretion and glucose sensitivity in INS-1E cells. Diabetes Obes Metab 16, 602-612.

102. Song Z, Wang H, Zhu L, et al. (2015) Curcumin improves high glucose-induced INS-1 cell insulin resistance via activation of insulin signaling. Food Funct 6, 461-469.

103. Zhang J, Du Y, Wu C, et al. (2010) Curcumin promotes apoptosis in human lung adenocarcinoma cells through miR-186* signaling pathway. Oncol Rep 24, 1217-1223.

104. Sun M, Estrov Z, Ji Y, et al. (2008) Curcumin (diferuloylmethane) alters the expression profiles of microRNAs in human pancreatic cancer cells. Mol Cancer Ther 7, 464-473.

105. Choi MS, Jung UJ, Yeo J, et al. (2008) Genistein and daidzein prevent diabetes onset by elevating insulin level and altering hepatic gluconeogenic and lipogenic enzyme activities in non-obese diabetic (NOD) mice. Diabetes Metab Res Rev 24, $74-81$.

106. Milenkovic D, Deval C, Gouranton E, et al. (2012) Modulation of miRNA expression by dietary polyphenols in apoE deficient mice: a new mechanism of the action of polyphenols. PLOS ONE 7, e29837. 
107. Stull AJ, Cash KC, Johnson WD, et al. (2010) Bioactives in blueberries improve insulin sensitivity in obese, insulinresistant men and women. J Nutr 140, 1764-1768.

108. Wedick NM, Pan A, Cassidy A, et al. (2012) Dietary flavonoid intakes and risk of type 2 diabetes in US men and women. Am J Clin Nutr 95, 925-933.

109. Lappas M (2014) Effect of pre-existing maternal obesity, gestational diabetes and adipokines on the expression of genes involved in lipid metabolism in adipose tissue. Metabolism 63, 250-262.

110. D'Ippolito S, Tersigni C, Scambia G, et al. (2012) Adipokines, an adipose tissue and placental product with biological functions during pregnancy. Biofactors 38, 14-23.

111. Hauguel-de Mouzon S \& Guerre-Millo M (2006) The placenta cytokine network and inflammatory signals. Placenta 27, 794-798.

112. Friis CM, Paasche Roland MC, Godang K, et al. (2013) Adiposity-related inflammation: effects of pregnancy. Obesity 21, E124-E130.

113. Barbour LA, McCurdy CE, Hernandez TL, et al. (2007) Cellular mechanisms for insulin resistance in normal pregnancy and gestational diabetes. Diabetes Care 30, Suppl. 2, S112-S119.

114. Li HP, Chen X \& Li MQ (2013) Gestational diabetes induces chronic hypoxia stress and excessive inflammatory response in murine placenta. Int J Clin Exp Pathol 6, 650-659.

115. Xu Y, Jin B, Sun L, et al. (2014) The expression of FoxO1 in placenta and omental adipose tissue of gestational diabetes mellitus. Exp Clin Endocrinol Diabetes 122, 287-294.

116. Miehle K, Stepan H \& Fasshauer M (2012) Leptin, adiponectin and other adipokines in gestational diabetes mellitus and pre-eclampsia. Clin Endocrinol 76, 2-11.

117. Retnakaran R, Hanley AJ, Raif N, et al. (2004) Reduced adiponectin concentration in women with gestational diabetes: a potential factor in progression to type 2 diabetes. Diabetes Care 27, 799-800.

118. Rasouli N \& Kern PA (2008) Adipocytokines and the metabolic complications of obesity. J Clin Endocrinol Metab 93, S64-S73.

119. Lacroix M, Battista MC, Doyon M, et al. (2013) Lower adiponectin levels at first trimester of pregnancy are associated with increased insulin resistance and higher risk of developing gestational diabetes mellitus. Diabetes Care 36, $1577-1583$.

120. Hedderson MM, Darbinian J, Havel PJ, et al. (2013) Low prepregnancy adiponectin concentrations are associated with a marked increase in risk for development of gestational diabetes mellitus. Diabetes Care 36, 3930-3937.

121. Yamauchi T, Kamon J, Minokoshi Y, et al. (2002) Adiponectin stimulates glucose utilization and fatty-acid oxidation by activating AMP-activated protein kinase. Nat Med 8, 1288-1295.

122. Visiedo F, Bugatto F, Sanchez V, et al. (2013) High glucose levels reduce fatty acid oxidation and increase triglyceride accumulation in human placenta. Am J Physiol Endocrinol Metab 305, E205-E212.

123. Astapova O \& Leff $\mathrm{T}$ (2012) Adiponectin and PPARgamma: cooperative and interdependent actions of two key regulators of metabolism. Vitam Horm 90, 143-162.

124. Berg AH \& Scherer PE (2005) Adipose tissue, inflammation, and cardiovascular disease. Circ Res 96, 939-949.

125. Aye IL, Rosario FJ, Powell TL, et al. (2015) Adiponectin supplementation in pregnant mice prevents the adverse effects of maternal obesity on placental function and fetal growth. Proc Natl Acad Sci U S A 112, 12858-12863.
126. Li FY, Cheng KK, Lam KS, et al. (2011) Cross-talk between adipose tissue and vasculature: role of adiponectin. Acta Physiol (Oxf) 203, 167-180.

127. Lepercq J, Cauzac M, Lahlou N, et al. (1998) Overexpression of placental leptin in diabetic pregnancy: a critical role for insulin. Diabetes 47, 847-850.

128. Lappas M (2014) Markers of endothelial cell dysfunction are increased in human omental adipose tissue from women with pre-existing maternal obesity and gestational diabetes. Metabolism 63, 860-873.

129. Qiu C, Williams MA, Vadachkoria S, et al. (2004) Increased maternal plasma leptin in early pregnancy and risk of gestational diabetes mellitus. Obstet Gynecol 103, 519-525.

130. Al-Badri MR, Zantout MS \& Azar ST (2015) The role of adipokines in gestational diabetes mellitus. Ther $A d v$ Endocrinol Metab 6, 103-108.

131. Saucedo R, Zarate A, Basurto L, et al. (2011) Relationship between circulating adipokines and insulin resistance during pregnancy and postpartum in women with gestational diabetes. Arch Med Res 42, 318-323.

132. Bao W, Baecker A, Song Y, et al. (2015) Adipokine levels during the first or early second trimester of pregnancy and subsequent risk of gestational diabetes mellitus: a systematic review. Metabolism 64, 756-764.

133. Xu J, Zhao YH, Chen YP, et al. (2014) Maternal circulating concentrations of tumor necrosis factor-alpha, leptin, and adiponectin in gestational diabetes mellitus: a systematic review and meta-analysis. ScientificWorldJournal 2014, 926932.

134. Hegyi K, Fulop K, Kovacs K, et al. (2004) Leptin-induced signal transduction pathways. Cell Biol Int 28, 159-169.

135. Santos-Alvarez J, Goberna R \& Sanchez-Margalet V (1999) Human leptin stimulates proliferation and activation of human circulating monocytes. Cell Immunol 194, 6-11.

136. Wojcik M, Chmielewska-Kassassir M, Grzywnowicz K, et al. (2014) The relationship between adipose tissue-derived hormones and gestational diabetes mellitus (GDM). Endokrynol Pol 65, 134-142.

137. Li YY, Xiao R, Li CP, et al. (2015) Increased plasma levels of FABP4 and PTEN is associated with more severe insulin resistance in women with gestational diabetes mellitus. Med Sci Monit 21, 426-431.

138. Landberg R, Naidoo N \& van Dam RM (2012) Diet and endothelial function: from individual components to dietary patterns. Curr Opin Lipidol 23, 147-155.

139. Favero G, Paganelli C, Buffoli B, et al. (2014) Endothelium and its alterations in cardiovascular diseases: life style intervention. Biomed Res Int 2014, 801896.

140. Schwingshackl L \& Hoffmann G (2014) Mediterranean dietary pattern, inflammation and endothelial function: a systematic review and meta-analysis of intervention trials. Nutr Metab Cardiovasc Dis 24, 929-939.

141. Caselli C (2014) Role of adiponectin system in insulin resistance. Mol Genet Metab 113, 155-160.

142. Wang A, Liu M, Liu X, et al. (2011) Up-regulation of adiponectin by resveratrol: the essential roles of the Akt/FOXO1 and AMP-activated protein kinase signaling pathways and DsbA-L. J Biol Chem 286, 60-66.

143. Eseberri I, Lasa A, Churruca I, et al. (2013) Resveratrol metabolites modify adipokine expression and secretion in 3T3-L1 pre-adipocytes and mature adipocytes. PLOS ONE $\mathbf{8}$, e63918.

144. Kang L, Heng W, Yuan A, et al. (2010) Resveratrol modulates adipokine expression and improves insulin sensitivity in adipocytes: relative to inhibition of inflammatory responses. Biochimie 92, 789-796. 
145. Peng XL, Qu W, Wang LZ, et al. (2014) Resveratrol ameliorates high glucose and high-fat/sucrose diet-induced vascular hyperpermeability involving Cav-1/eNOS regulation. PLOS ONE 9, e113716.

146. Liu Y, Li D, Zhang Y, et al. (2014) Anthocyanin increases adiponectin secretion and protects against diabetes-related endothelial dysfunction. Am J Physiol Endocrinol Metab 306, E975-E988.

147. Jin T, Kim OY, Shin MJ, et al. (2014) Fisetin up-regulates the expression of adiponectin in 3T3-L1 adipocytes via the activation of silent mating type information regulation 2 homologue 1 (SIRT1)-deacetylase and peroxisome proliferator-activated receptors (PPARs). J Agri Food Chem 62, 10468-10474

148. Khan N, Syed DN, Ahmad N, et al. (2013) Fisetin: a dietary antioxidant for health promotion. Antioxid Redox Signal 19, 151-162.

149. Scoditti E, Massaro M, Carluccio MA, et al. (2015) Additive regulation of adiponectin expression by the Mediterranean diet olive oil components oleic acid and hydroxytyrosol in human adipocytes. PLOS ONE 10, e0128218.

150. Lamy S, Ouanouki A, Beliveau R, et al. (2014) Olive oil compounds inhibit vascular endothelial growth factor receptor-2 phosphorylation. Exp Cell Res 322, 89-98.

151. Niwa T, Yokoyama S, Ito T, et al. (2010) Reduction of leptin secretion by soy isoflavonoids in murine adipocytes in vitro. Phytochem Lett 3, 122-125.

152. Yanagisawa M, Sugiya M, Iijima H, et al. (2012) Genistein and daidzein, typical soy isoflavones, inhibit TNF-alphamediated downregulation of adiponectin expression via different mechanisms in 3T3-L1 adipocytes. Mol Nutr Food Res 56, 1783-1793.

153. Chen J, Mo H, Guo R, et al. (2014) Inhibition of the leptin-induced activation of the p38 MAPK pathway contributes to the protective effects of naringin against high glucose-induced injury in $\mathrm{H} 9 \mathrm{c} 2$ cardiac cells. Int J Mol Med 33, 605-612.

154. Mahmoud AM, Ashour MB, Abdel-Moneim A, et al. (2012) Hesperidin and naringin attenuate hyperglycemia-mediated oxidative stress and proinflammatory cytokine production in high fat fed/streptozotocin-induced type 2 diabetic rats. J Diabetes Complications 26, 483-490.

155. Sakane N, Kotani K, Tsuzaki K, et al. (2014) Equol producers can have low leptin levels among prediabetic and diabetic females. Ann Endocrinol (Paris) 75, 25-28.

156. Llaneza P, Gonzalez C, Fernandez-Inarrea J, et al. (2011) Soy isoflavones, diet and physical exercise modify serum cytokines in healthy obese postmenopausal women. Phytomedicine 18, 245-250.

157. Gupta SC, Tyagi AK, Deshmukh-Taskar P, et al. (2014) Downregulation of tumor necrosis factor and other proinflammatory biomarkers by polyphenols. Arch Biochem Biophys 559, 91-99.

158. Rebholz SL, Burke KT, Yang Q, et al. (2011) Dietary fat impacts fetal growth and metabolism: uptake of chylomicron remnant core lipids by the placenta. Am J Physiol Endocrinol Metab 301, E416-E425.

159. Jones ML, Mark PJ \& Waddell BJ (2014) Maternal dietary omega-3 fatty acids and placental function. Reproduction 147, R143-R152.

160. Herrera E \& Ortega-Senovilla H (2010) Disturbances in lipid metabolism in diabetic pregnancy - are these the cause of the problem? Best Pract Res Clin Endocrinol Metab 24, 515-525.

161. Haggarty P (2010) Fatty acid supply to the human fetus. Ann Rev Nutr 30, 237-255.
162. Gil-Sanchez A, Demmelmair H, Parrilla JJ, et al. (2011) Mechanisms involved in the selective transfer of long chain polyunsaturated fatty acids to the fetus. Front Genet 2, 57.

163. Pagan A, Prieto-Sanchez MT, Blanco-Carnero JE, et al. (2013) Materno-fetal transfer of docosahexaenoic acid is impaired by gestational diabetes mellitus. Am J Physiol Endocrinol Metab 305, E826-E833.

164. Araujo JR, Correia-Branco A, Ramalho C, et al. (2013) Gestational diabetes mellitus decreases placental uptake of long-chain polyunsaturated fatty acids: involvement of longchain acyl-CoA synthetase. J Nutr Biochem 24, 1741-1750.

165. Gauster M, Hiden U, van Poppel M, et al. (2011) Dysregulation of placental endothelial lipase in obese women with gestational diabetes mellitus. Diabetes 60, 2457-2464.

166. Barrett HL, Kubala MH, Scholz Romero K, et al. (2014) Placental lipases in pregnancies complicated by gestational diabetes mellitus (GDM). PLOS ONE 9, e104826.

167. Duttaroy AK (2009) Transport of fatty acids across the human placenta: a review. Prog Lipid Res 48, 52-61.

168. Jawerbaum A \& Capobianco E (2011) Review: effects of PPAR activation in the placenta and the fetus: implications in maternal diabetes. Placenta 32, Suppl. 2, S212-S217.

169. Simopoulos AP (2011) Evolutionary aspects of diet: the omega-6/omega-3 ratio and the brain. Mol Neurobiol 44, 203-215.

170. Calder PC (2012) Mechanisms of action of ( $n-3)$ fatty acids. J Nutr 142, 592S-599S

171. Russo GL (2009) Dietary $n-6$ and $n-3$ polyunsaturated fatty acids: from biochemistry to clinical implications in cardiovascular prevention. Biochem Pharmacol 77, 937-946.

172. Zinati Z, Zamansani F, Hossein KayvanJoo A, et al. (2014) New layers in understanding and predicting alpha-linolenic acid content in plants using amino acid characteristics of omega-3 fatty acid desaturase. Comput Biol Med 54, 14-23.

173. Burns-Whitmore B, Haddad E, Sabate J, et al. (2014) Effects of supplementing $n-3$ fatty acid enriched eggs and walnuts on cardiovascular disease risk markers in healthy free-living lacto-ovo-vegetarians: a randomized, crossover, free-living intervention study. Nutr J 13, 29.

174. Mayneris-Perxachs J, Sala-Vila A, Chisaguano M, et al. (2014) Effects of 1-year intervention with a Mediterranean diet on plasma fatty acid composition and metabolic syndrome in a population at high cardiovascular risk. PLOS ONE 9, e85202.

175. Galli C \& Marangoni F (2006) $N-3$ fatty acids in the Mediterranean diet. Prostaglandins Leukot Essent Fatty Acids 75, 129-133.

176. Uddin MK, Juraimi AS, Hossain MS, et al. (2014) Purslane weed (Portulaca oleracea): a prospective plant source of nutrition, omega-3 fatty acid, and antioxidant attributes. Scientific WorldJournal 2014, 951019.

177. Panagiotakos D, Kalogeropoulos N, Pitsavos C, et al. (2009) Validation of the MedDietScore via the determination of plasma fatty acids. Int J Food Sci Nutr 60, Suppl. 5, 168-180.

178. Feart C, Torres MJ, Samieri C, et al. (2011) Adherence to a Mediterranean diet and plasma fatty acids: data from the Bordeaux sample of the Three-City study. BrJ Nutr 106, 149-158.

179. Ambring A, Johansson M, Axelsen M, et al. (2006) Mediterranean-inspired diet lowers the ratio of serum phospholipid $n-6$ to $n-3$ fatty acids, the number of leukocytes and platelets, and vascular endothelial growth factor in healthy subjects. Am J Clin Nutr 83, 575-581.

180. Scoditti E, Capurso C, Capurso A, et al. (2014) Vascular effects of the Mediterranean diet-part II: role of omega-3 fatty acids and olive oil polyphenols. Vascul Pharmacol 63 , $127-134$. 
181. Koletzko B, Lien E, Agostoni C, et al. (2008) The roles of long-chain polyunsaturated fatty acids in pregnancy, lactation and infancy: review of current knowledge and consensus recommendations. J Perinat Med 36, 5-14.

182. Pietrantoni E, Del Chierico F, Rigon G, et al. (2014) Docosahexaenoic acid supplementation during pregnancy: a potential tool to prevent membrane rupture and preterm labor. Int J Mol Sci 15, 8024-8036.

183. Carvajal JA (2014) Docosahexaenoic acid supplementation early in pregnancy may prevent deep placentation disorders. Biomed Res Int 2014, 526895.

184. Mohammadi E, Rafraf M, Farzadi L, et al. (2012) Effects of omega-3 fatty acids supplementation on serum adiponectin levels and some metabolic risk factors in women with polycystic ovary syndrome. Asia Pac J Clin Nutr 21, 511-518.

185. Lu J, Borthwick F, Hassanali Z, et al. (2011) Chronic dietary $n$-3 PUFA intervention improves dyslipidaemia and subsequent cardiovascular complications in the JCR:LA-cp rat model of the metabolic syndrome. Br J Nutr 105, 1572-1582.

186. Min Y, Djahanbakhch O, Hutchinson J, et al. (2014) Effect of docosahexaenoic acid-enriched fish oil supplementation in pregnant women with type 2 diabetes on membrane fatty acids and fetal body composition-double-blinded randomized placebo-controlled trial. Diabet Med 31, 1331-1340.

187. Recchiuti A \& Serhan CN (2012) Pro-resolving lipid mediators (SPMs) and their actions in regulating miRNA in novel resolution circuits in inflammation. Front Immunol 3, 298.

188. Jones ML, Mark PJ, Keelan JA, et al. (2013) Maternal dietary omega-3 fatty acid intake increases resolvin and protectin levels in the rat placenta. J Lipid Res 54, 2247-2254.

189. Keelan JA, Mas E, D’Vaz N, et al. (2015) Effects of maternal $n$-3 fatty acid supplementation on placental cytokines, pro-resolving lipid mediators and their precursors. Reproduction 149, 171-178.

190. Jamilian M, Samimi M, Kolahdooz F, et al. (2016) Omega-3 fatty acid supplementation affects pregnancy outcomes in gestational diabetes: a randomized, double-blind, placebocontrolled trial. J Matern Fetal Neonatal Med 29, 669-675.

191. Jia X, Pakseresht M, Wattar N, et al. (2015) Women who take $n-3$ long-chain polyunsaturated fatty acid supplements during pregnancy and lactation meet the recommended intake. App Physiol Nutr Metab 40, 474-481.

192. Higuchi T, Shirai N, Saito M, et al. (2008) Levels of plasma insulin, leptin and adiponectin, and activities of key enzymes in carbohydrate metabolism in skeletal muscle and liver in fasted ICR mice fed dietary $n-3$ polyunsaturated fatty acids. J Nutr Biochem 19, 577-586.

193. O’Tierney-Ginn P, Roberts V, Gillingham M, et al. (2015) Influence of high fat diet and resveratrol supplementation on placental fatty acid uptake in the Japanese macaque. Placenta 36, 903-910.

194. Bellenger J, Bellenger S, Bataille A, et al. (2011) High pancreatic $n-3$ fatty acids prevent STZ-induced diabetes in fat-1 mice: inflammatory pathway inhibition. Diabetes $\mathbf{6 0}$, 1090-1099.

195. Oh DY, Talukdar S, Bae EJ, et al. (2010) GPR120 is an omega-3 fatty acid receptor mediating potent anti-inflammatory and insulin-sensitizing effects. Cell 142, 687-698.

196. Li K, Huang T, Zheng J, et al. (2014) Effect of marine-derived n-3 polyunsaturated fatty acids on C-reactive protein, interleukin 6 and tumor necrosis factor alpha: a meta-analysis. PLOS ONE 9, e88103.

197. Harris WS (2014) Achieving optimal $n$-3 fatty acid status: the vegetarian's challenge... or not. Am J Clin Nutr 100, Suppl. 1, 449S-452S.

198. Rajaram S (2014) Health benefits of plant-derived alphalinolenic acid. Am J Clin Nutr 100, Suppl. 1, 443S-448S.

199. Adarme-Vega TC, Lim DK, Timmins M, et al. (2012) Microalgal biofactories: a promising approach towards sustainable omega-3 fatty acid production. Microb Cell Fact 11, 96.

200. Lenihan-Geels G, Bishop KS \& Ferguson LR (2013) Alternative sources of omega-3 fats: can we find a sustainable substitute for fish? Nutrients 5, 1301-1315. 